\title{
A review of scroll expander geometries and their performance
}

\author{
Simon Emhardt, Guohong Tian, John Chew \\ Department of Mechanical Engineering Sciences, University of Surrey, Guildford, Surrey, GU2 7XH, UK
}

\section{Corresponding Author:}

Dr. Guohong Tian

Address: Department of Mechanical Engineering Sciences, University of Surrey

388 Stag Hill, Guildford, Surrey, GU2 7XH, UK

Tel: $+44(0) 1483689283$

E-mail: g.tian@surrey.ac.uk

Keywords:

Organic Rankine cycle, Scroll expander, Built-in volume ratio, Pressure ratio, Variable wall thickness design

\begin{abstract}
Scroll expanders are currently attracting interest for integration in small scale organic Rankine cycle (ORC) waste heat recovery applications and have been subject to significant research over the last two decades. The most common geometrical design uses a scroll profile generated by the involute of a circle with a constant wall thickness. A major disadvantage of this approach is that the increase of the geometric expansion ratio is constrained, since it is accompanied with a large increase in the scroll profile length and is associated with a decreased efficiency. In this paper, the published literature related to scroll expander geometry is reviewed. Investigations regarding the influence of varying scroll geometrical parameters on the performance of scroll expanders with a constant wall thickness are first examined. The use of variable wall thicknesses and their effects on the performance are then considered. Finally, the impact of scroll expander geometries using unconventional scroll profiles and scroll tip shape variations on the performance is discussed and summarised. The major conclusion to be drawn from this review is that scroll expanders with variable wall thickness scrolls should be further designed and developed. It is possible to increase the geometric expansion ratio without increasing the length of the scroll profiles. CFD simulations are a promising tool to illustrate and understand the non-uniform and asymmetric inner flow and temperature fields. The related benefits could lead to scroll devices with variable wall thickness not only improving the performance of organic Rankine cycle (ORC) systems but also opening a broad new field of applications such as refrigeration cycles and other power cycles where a high pressure ratio is preferred.
\end{abstract}

\section{Contents}

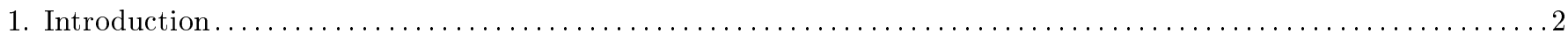

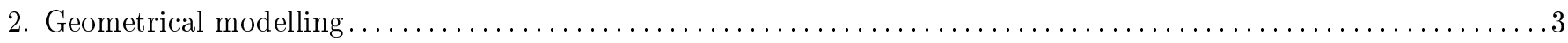

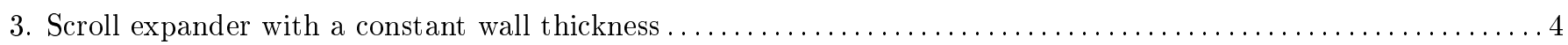

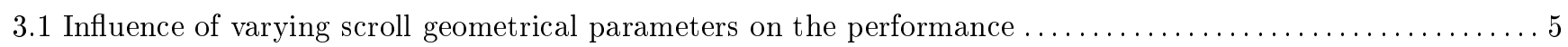

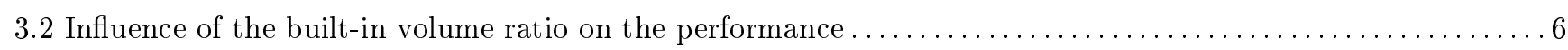

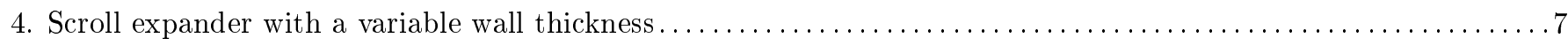

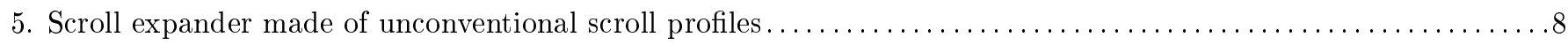

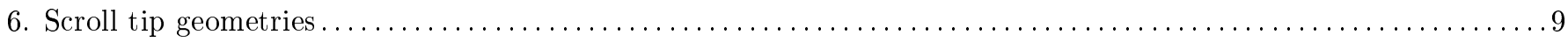

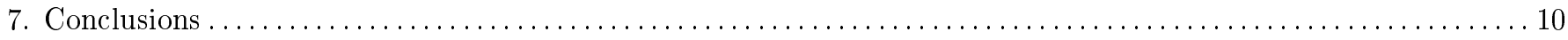

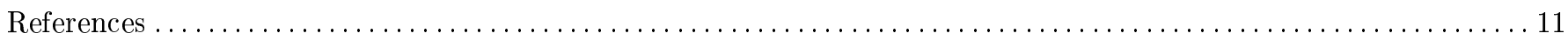




\section{Introduction}

Electrical power can be generated in a regenerative manner from middle to low grade waste heat with the help of organic Rankine cycle (ORC) technology. Such systems can be operated by energy lost from sources such as internal combustion engine exhaust gases [1,2], biomass combustion [3,4], industrial waste heat [5,6], solar thermal energy [7,8] and geothermal heat $[9,10]$. The choice of the expansion machine is of key importance to ORC performance.

There are two categories of suitable expansion machines for ORC-based systems. These are the velocity type including axial and radial-inflow turbines, and positive displacement devices, such as screw expanders, reciprocating piston expanders, rotary vane expanders and scroll expanders [11]. Compared to the competitors, scroll expanders may have positive properties such as high efficiency, high pressure ratio, relatively low flow rate, low level of noise and vibration due to fewer moving parts and the symmetric working chamber layout, and much lower rotational speed. Furthermore the ease and low cost of manufacture, lack of valves, tolerance to two-phase flows, and high reliability make them suitable for applications in small or micro ORC systems in the output power range from several hundred watts up to $10 \mathrm{~kW}$ [10-14]. In contrast low capacity and lubrication needs may disadvantage scroll expanders for larger systems [14]. The pressure ratio is also too low for some applications. Some authors defined the imposed pressure ratio between scroll expander inlet and outlet as the expansion ratio. It has been renamed into pressure ratio in this paper in order to avoid any misunderstanding.

The principle of a scroll expander is illustrated in Fig.1. This shows two interleaving scrolls. As one scroll orbits, a volume of air initially trapped in a volume at the centre of the device expands and moves radially outwards as the movement proceeds. This is shown by the time sequence for an anticlockwise orbiting movement. A clockwise orbiting movement would produce the reverse effect with the device operating as a compressor.

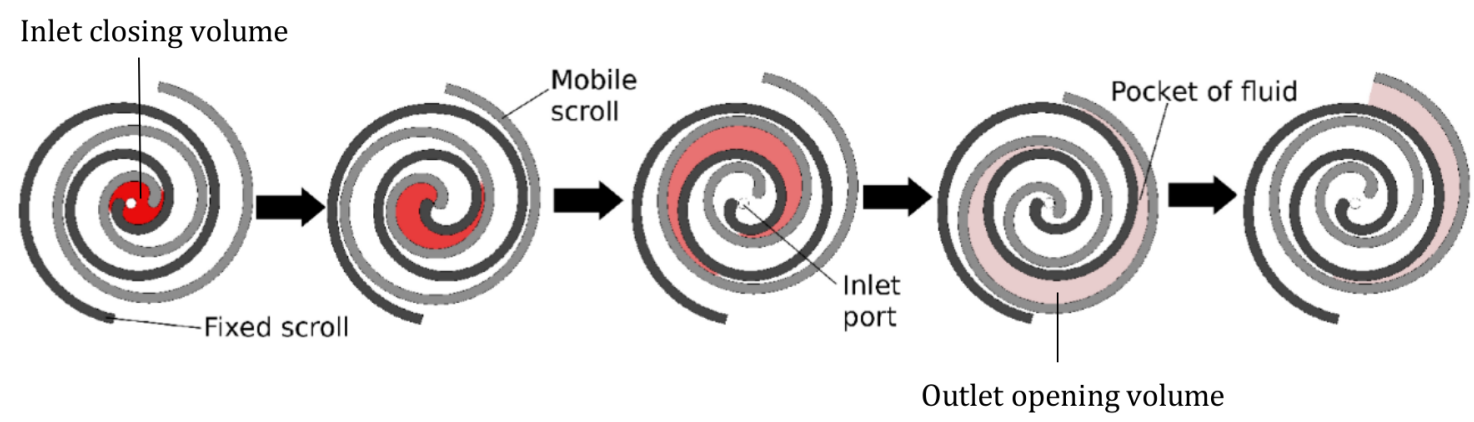

Figure 1: The principle of a scroll expander [15]

To date, in most of the published research on scroll expanders, off-the-shelf scroll compressors have been modified and driven in the opposite direction as expanders [16-25]. The main reason for this approach is to reduce cost. Song et al. [26] divided scroll compressors into different types, namely hermetic refrigeration scroll compressors, semi-hermetic automotive $\mathrm{A} / \mathrm{C}$ compressors, open-drive automotive $\mathrm{A} / \mathrm{C}$ compressors and open-drive scroll air compressors. Hence, the conversion to expanders is dependent on the scroll compressor type. Moreover, scroll machines can be categorised into kinematically constrained and compliant scroll devices. The clearance gap between the orbiting and fixed scroll in a kinematically constrained scroll design is fixed to a small value permanently during the operation. In a compliant scroll design, movement of the fixed scroll in the axial direction and the orbiting scroll in the radial direction is possible. This allows the device to deal with liquid flashing and to ride over debris [27]. Whereas researchers place greater emphasis on basic and fundamental research, a few companies such as OBRIST Engineering [28], Exoés [29], Air Squared, Inc. [30], Eneftech Innovation [31] and ECR International [32] aim to implement commercial solutions of scroll expander on the market.

Scroll expander has a certain tolerance to liquid droplets. Hence, the potential working fluids can be slightly wet at the expander outlet. Bao and Zhao (2013) [14] provided a thorough and comprehensive review about a wide range of suitable working fluids including the impact of their physical and thermodynamic properties on the ORC system performance. Apart from the scroll expander classification, Song et al. (2015) [26] also covered a huge number of references in their literature review regarding the thermodynamic analysis of scroll machines and the prediction of occurring mechanisms inside the scroll volumes by means of experimental studies, theoretical modelling and CFD simulations. Recently, the CFD technology began making inroads into the scroll machine development [33-42]. It can be a promising technology to further optimise the scroll expander geometry and improve the thermodynamic performance due to the opportunity to more easily depict the asymmetric inner flow and temperature field compared 
to experimental investigations.

But a thorough understanding of the scroll geometry itself is essential for the design and optimisation of scroll machines. Léon Creux filed a patent application for his invention of the scroll-type machine used for compressing air or refrigerant in 1905 [43]. He described the scroll profile by the involute of a circle, which is still the most commonly used approach. Scroll designs can also be defined with profiles such as polygon or semi-circle involutes, offset spliced involutes [44], involute curves combined with circular arcs [45], algebraic spirals, modified Archimedes spirals [46] and scroll designs with varying wall thicknesses.

The scroll geometry, with a fixed built-in volume ratio defined as the discharge chamber volume at the beginning of the discharge process divided by the maximum suction chamber volume, is an important design parameter. Overexpansion can occur when the pressure gradient induces the fluid to flow back and results in a recompression. Underexpansion can occur when the pressure in the expansion chamber is higher than the pressure in the discharge pipe. Over-expansion is particularly detrimental for the efficiency [13,47]. The maximum shaft power and isentropic efficiency of scroll machines also depends on the choice of the working fluid, rotational speed, mechanical and leakage losses and internal heat transfer effects [10]. Furthermore, high built-in volume ratios may lead to an improved system performance of ORC units as a result of a more thorough expansion which enables the ORC systems to be more suitable for two-phase flows and more applicable to small- and micro-scale systems. In addition, a higher efficiency at a lower rotational speed can be achieved which in turn simplifies the connection of the reduction gear with the generator, especially in comparison to a turbine.

This paper reviews the literature available for scroll expanders and discusses previous work from the viewpoint of the scroll machine geometry. It also considers a significant number of publications on scroll compressors as they share common characteristics. In section 2, publications related to geometrical modelling are discussed. In section 3 , the influence of varying scroll geometrical parameters on the performance of scroll expanders with constant wall thickness is analysed. Furthermore, scroll expander geometries with variable wall thicknesses are examined in section 4 . The comparison of scroll expander geometries using unconventional scroll profiles is presented in section 5., while the effect of the scroll tip shape on the performance is summarised in section 6 .

\section{Geometrical modelling}

A geometrical model includes the equations to generate the scroll profiles for the description of the geometry. This is the basis for the development of analytical expressions for the chamber volumes and internal leakages depending on the orbiting angle during the scroll working process. A simplified and reliable geometrical model is required in order to combine and couple it with a thermodynamic model to capture the fluid thermal effects in terms of pressure fields, mass flows, heat transfer losses and other effects on the performance. Compared to scroll expanders, scroll compressors have been more widely studied and therefore provide the necessary knowledge which can be used to design scroll expanders. Hence, an overview of the development of scroll compressor models is given in the following sub-section. The second sub-section considers the expander models which are based on the geometrical approaches of the compressor models.

\section{Scroll compressor models}

Many researchers have developed mathematical models of scroll machines with scroll designs described by an involute of a circle with a constant wall thickness to investigate and understand the influence of the scroll geometry on the performance. These scroll profiles are based on a mathematical differential equation (Eqs.(1)) which relates the tangential distance between the inner and outer involute $L$ and the base circle radius $a$.

$$
\frac{\delta L(\varphi)}{\delta \varphi}=a
$$

The individual coordinate points $(x)$ and $(y)$ on the two circle of involutes can be determined by using Eqs.(2) and Eqs.(3)

$$
\begin{aligned}
& x=a(\cos (\varphi)+\varphi \sin (\varphi)) \\
& y=a(\sin (\varphi)-\varphi \cos (\varphi))
\end{aligned}
$$

in which $\varphi$ is defined as the involute angle. For example, Hayano et al. (1986) [48] captured the change of the chamber volume during the compression process by developing several different equations depending on the orbiting angle. The scroll profiles were approximated with several semi-circles. In 1984 and 1986, Morishita et al. [49, 50] used a similar 
approach to calculate the change of the chamber volume not only during the compression but also the discharge process and the function can be expressed as

$$
V_{i}(\theta)=\pi p(p-2 t) h\left[(2 i-1)-\frac{\theta}{\pi}\right]
$$

where $p$ describes the scroll pitch $p=2 \pi a, t$ the scroll wall thickness, $h$ the scroll profile height and $\theta$ the orbiting angle. The initial angle of the inner involute $\alpha_{i}$ was equated with the negative initial angle of the outer involute $\alpha_{0}\left(\alpha_{i}=-\alpha_{0}\right)$ as shown in Fig.2. The generation of the scroll profiles and the associated modelling complexity was simplified due to the elimination of one parameter.

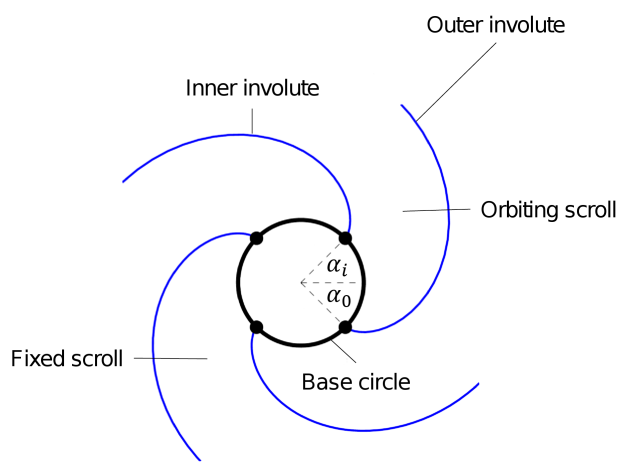

Figure 2: Initial angles of the involutes [51]

Tojo et al. (1986) [52], Etemad and Nieter (1988) [53] and Nieter (1988) [54] conducted further simulations using the geometrical model of Morishita [49,50]. Whereas all the previous investigations were based on the assumption of a quasi-static suction process, Nieter (1988) [54] constructed a model which for the first time took the instantaneous flow rate and the pressure losses in the suction chamber into account. Another analytical analysis of Nieter and Gagne (1992) [55] was more complete due to the fact that the position of the discharge port was considered. Moreover, a transfer matrix approach from the frequency domain was implemented into the geometric model to examine the correlation between the pressure pulsations in the compressor discharge manifold and the pulsating flow characteristics in the discharge port. Although the authors pointed out its significance and provided a detailed description of the matrix approach, no evaluation of the particular effects on the compressor performance or the manifold design was presented in their work. Compared to previous studies which used the same set of equations to model the compression and discharge process respectively, Hirano et al. (1988) [56] and Yanagisawa et al. (1990) [57] built a geometrical model which treated and calculated the volume change in the suction, compression and discharge chambers separately by using three different sets of equations. Moreover, the calculation of each chamber volume change was reduced to just one function rather than a set of several equations in all three cases. The change of the compression chamber volume reads

$$
V_{c}=2 \pi h a r_{o}\left(2 \varphi_{e}-2 \theta-3 \pi\right)
$$

where $r_{o}$ is the orbiting radius of the moving scroll and $\varphi_{e}$ the involute ending angle. Hence the computational complexity was reduced, although the initial angle of the inner involute was still equated with the negative initial angle of the outer involute.

Zhu et al. (1994) [58] combined the suction process approach of Yanagisawa et al. [57] and a similar approach to Morishita's [49,50] compression and discharge process modelling to develop a scroll compressor for higher pressure ratios than in previous studies. The model allowed modification of the scroll height and the position and shape of the discharge port. The compression and discharge process in the geometrical model of Liu et al. (1996) [59] was also related to the approach of Morishita's [49,50] model. In this study the suction pressure losses were determined by considering the influence of a back-pressure mechanism on the suction pressure. Following the geometrical model approach of Yanagisawa [57], Halm (1997) [60] and Chen et al. (2002) [61,62] integrated individual models for the compression process, internal leakages, heat transfer and overall energy balance into their thermodynamic model in order to make it more complete than in previous studies. The change of the compression chamber volume can be expressed as

$$
V_{c}=2 \pi h a r_{o}\left(2 \varphi_{e}-2 \theta-\frac{7}{2} \pi\right)
$$

All of the aforementioned geometric models only estimated the leakages during the compression process and neglected them in the suction and discharge processes. A distinction between tangential and radial leakage areas was included. According to Wang et al. (2005) [63], it was difficult to use these models in combination with a numerical 
control machine to manufacture the scrolls. The main reason was the need for arrangement of the scrolls in a certain position and angle. That is why a geometrical model with arbitrary initial involute angles was for the first time constructed by the authors as visualised in Fig.3.

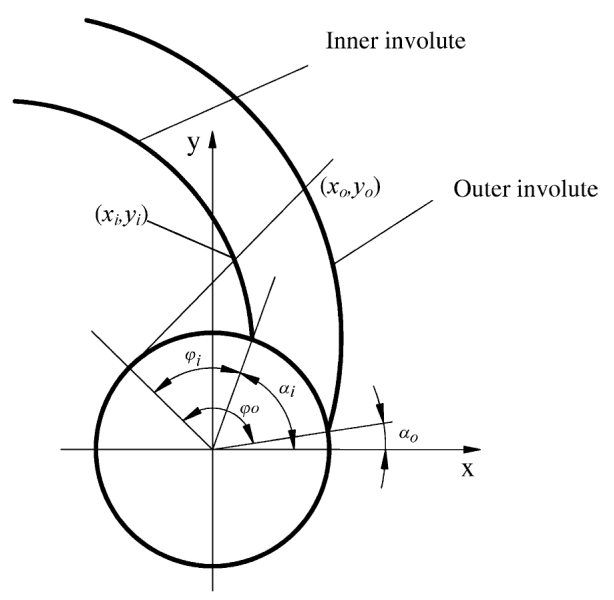

Figure 3: Arbitrary initial involute angles [63]

The individual coordinate points $x_{i, o}$ and $y_{i, o}$ on the two circle of involutes can be determined by using Eqs.(7)-Eqs.(10) respectively.

$$
\begin{gathered}
x_{i}=a\left(\cos \left(\varphi_{i}+\alpha_{i}\right)+\varphi_{i} \sin \left(\varphi_{i}+\alpha_{i}\right)\right) \\
y_{i}=a\left(\sin \left(\varphi_{i}+\alpha_{i}\right)-\varphi_{i} \cos \left(\varphi_{i}+\alpha_{i}\right)\right) \\
x_{o}=a\left(\cos \left(\varphi_{o}+\alpha_{o}\right)+\varphi_{o} \sin \left(\varphi_{o}+\alpha_{o}\right)\right) \\
y_{o}=a\left(\sin \left(\varphi_{o}+\alpha_{o}\right)-\varphi_{o} \cos \left(\varphi_{o}+\alpha_{o}\right)\right)
\end{gathered}
$$

A subsection function was used to express the volume during the suction, compression and discharge processes including a mathematical representation of the tangential and radial leakage areas. The change of the volume during the compression process reads

$$
V_{c}=2 \pi h a r\left(2 \varphi_{e}-2 \theta-\left(\alpha_{i}+\alpha_{o}-\pi\right)\right.
$$

Hence, it was easier to model a larger variety of different scroll compressor geometries than with previous methods.

The coordinate system of the conventional reference frame had its origin at the base circle of the fixed involute. Inspired by the geometry description of Halm [60] and based on the model of Gravesen [64] for constant wall thicknesses, Blunier et al. $[65,66]$ constructed a geometrical model with a novel reference frame characterised by a coordinate system which has its origin at the symmetry centre of the scrolls. This approach provided exact analytical expressions of the compression and discharge chamber volumes and simplified the model. Many further publications related to scroll compressor geometrical models have used this geometrical approach. The ability to cope with complex profiles in turn led to an increased design flexibility for scrolls with constant wall thickness.

\section{Scroll expander models}

Geometrical scroll compressor models can be applied to scroll expanders due to the fact that the machine geometry is the same. The operation takes place in reverse direction in the expander. The individual chambers must be redefined from suction into discharge, compression into expansion and discharge into suction respectively. Tab.1 summarises the published research on scroll expander models. This clearly builds on the compressor modelling described above, with the first scroll expander models appearing around 2008. For a more accurate calculation of the chamber volume during the suction process of the scroll expander, Bell et al. [51,67,68] improved the models of Halm [60] and Chen et al. [61,62] by describing the scroll tip geometry in the suction area with two arcs and a tangent line instead of the previous approach of a simple tangent arc. The expander models of Lemort et al. [69] and Bell et al. [67] combine versions of the geometrical models of Halm [60] and Bell et al. [67] with thermodynamic modelling of the expansion process. The geometrical approach of Halm [60] was also implemented in another expander model by Lemort et al. (2009) [70]. This model was characterised by a control volume analysis linked with differential equations of mass and energy. The authors stated that the model could be used to improve the performance by means of modifying the scroll 
expander design, having advantages in terms of accuracy, low computational time and robustness. Both studies by Lemort have indicated that a better system performance could have been achieved by using an expander with a larger built-in volume ratio due to the associated opportunity of applying higher pressure ratios which are more suitable for Rankine cycle applications.

Other researchers have based models on Halm's [60] or Blunier et al.'s [65,66] geometric models, focussing on different aspects of performance [71-75]. Notably the combination of an increase of the suction chamber size by modifying the constant wall thickness and the extension of the scroll profile length to improve the performance of a scroll expander integrated in a hybrid pneumatic actuator system [71,72]. Legros et al. [73] pointed out that the prediction of the maximum isentropic efficiency is not only related to the built-in volume ratio and the corresponding pressure ratios but also dependent on flank/radial leakage and friction losses. The studies of Liu et al. [74] showed the ability to predict the optimum pressure ratio to avoid over- and underexpansion which was in agreement with experimental data. This study also illustrated that a longer scroll profile length is necessary to increase the inlet pressure and apply higher pressure ratios. The study by Guo [75] did not include a thermal analysis of the expansion process but it showed consistency of expansion and discharge chamber volume calculations with Bell's analytical predictions and that a dual arc tip with perfect meshing profile created a higher built-in volume ratio than a single arc tip.

The analytical and experimental validations in the scroll expander model studies have confirmed that the geometrical approaches of the compressor models can be successfully coupled and combined with a thermodynamic model in order to design expander geometry and predict the expander working process with a good accuracy. Moreover, the need for high built-in volume ratios for applications in small ORC systems has been demonstrated.

\section{Scroll expander with a constant wall thickness}

This section concerns scroll expander geometries with a constant wall thickness. The influence of varying scroll geometrical parameters such as the base circle radius, the scroll height or the scroll profile length on the performance are elaborated in the first sub-section. No discussion about the influence of different scroll profiles on the performance are included in this section due to the fact that only involute of circles have been considered. The orbiting radius of the moving scroll is specified by the wall thickness and the base circle radius. It can also be determined due to the distance between the origins of the two base circles. Hence, the orbiting radius is not examined in detail due to the dependency on the two other main parameters. There are different opportunities to generate the scroll tip designs which are discussed along with their effects on the performance in a separate section (6) of the paper.

Many authors have adjusted the operational parameters to improve the performance of a scroll expander geometry with a fixed built-in volume ratio. These studies are considered in the order of increasing built-in volume ratios in the second sub-section to compare the influence of the latter on performance.

\subsection{Influence of varying scroll geometrical parameters on the performance}

Only a few researchers have conducted investigations in terms of varying the geometrical parameters of scroll machines characterised by scroll profiles created by the involute of a circle with a constant wall thickness, as illustrated in Fig.4. In these studies, the thermodynamic cycle parameters, displacement volume, pressure ratio and the fluid properties were kept constant representing ORC system conditions. The basic structure of this type of scroll expander geometry is defined by the following main parameters:

- base circle radius $(a)$

- inner and outer involute initial angles $\left(\alpha_{i}\right.$ and $\left.\alpha_{o}\right)$

- scroll profile (only involute of circles are considered here)

- scroll profile height $(h)$

- scroll profile length

- scroll wall thickness $\left(t=a \cdot\left(\alpha_{i}-\alpha_{o}\right)\right)$

- orbiting radius of the moving scroll $\left(r_{o}=a \cdot \pi-t\right)$

- built-in volume ratio $\left(r_{v}\right.$, determined by the parameters above)

- scroll tip shape (determined by the parameters above) 
The table below (Tab.1) summarises studies of the influence of the scroll geometrical parameters on the scroll machine performance. The influence of each of the parameters in the left hand column is discussed in the sub-section below.

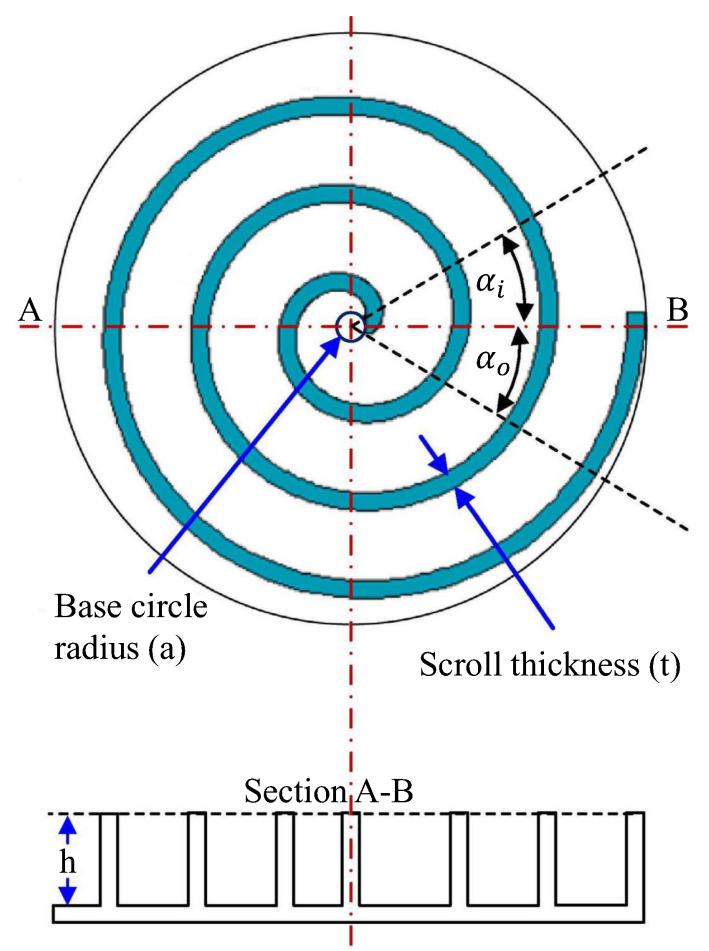

Figure 4: Scroll geometry with constant wall thickness [76]

Table 1: Influence of scroll geometrical parameters

\begin{tabular}{|c|c|c|}
\hline $\begin{array}{l}\text { Modified } \\
\text { parameter }\end{array}$ & Authors & Results and outcomes \\
\hline $\begin{array}{l}\text { base circle } \\
\text { radius }\end{array}$ & $\begin{array}{l}\text { - Puff and Kruger } \\
\text { (1992) } \\
\text { - Ishii et al. } \\
\quad(1992,1994,1996)\end{array}$ & $\begin{array}{l}\text { - increasing base circle radius } \\
\text { led to a larger suction volume } \\
\text { but also to a reduced } \eta_{\text {mech }}\end{array}$ \\
\hline $\begin{array}{l}\text { involute } \\
\text { initial angles }\end{array}$ & $\begin{array}{l}\text { - Etemad and Nieter } \\
(1989)\end{array}$ & $\begin{array}{l}\text { - decreasing influence of increasing } \\
\alpha_{0} \text { on the discharge velocity }\end{array}$ \\
\hline $\begin{array}{l}\text { scroll profile } \\
\text { height }\end{array}$ & $\begin{array}{l}\text { - Morishita and } \\
\text { Sugihara }(1986) \\
\text { - Etemad and } \\
\text { Nieter }(1989) \\
\text { - Ishii et al. } \\
\text { (1992,1994,1996) } \\
\text { - Puff and Kruger } \\
\text { (1992) } \\
\text { - VanderKooy } \\
\text { (2004) } \\
\text { - Zhu et al. } \\
\text { (1994) } \\
\text { - Tateishi et al. } \\
\text { (2006) } \\
\text { - Kuwahara et al. } \\
\text { (2017) }\end{array}$ & $\begin{array}{l}\text { - overturning moment of moving } \\
\text { scroll limited scroll height } h \\
\text { - the increase of the scroll height } h \\
\text { resulted in increasing gas forces } \\
\text { and flank leakages and decreasing } \\
\text { radial leakages } \\
\text { - decreasing scroll height } h \text { resulted } \\
\text { in increasing thrust loads } \\
\text { - } h \text { should be decreased in } \\
\text { the discharge region to apply } \\
\text { higher pressure ratios } \\
\text { - 3D scroll profile with varying scroll } \\
\text { heights improved the efficiency by } \\
5.5 \% \text { and the capacity by } 11 \%\end{array}$ \\
\hline $\begin{array}{l}\text { scroll profile } \\
\text { length }\end{array}$ & $\begin{array}{l}\text { - Clemente et al. } \\
\text { (2012) }\end{array}$ & $\begin{array}{l}\text { - higher pressure ratios due } \\
\text { to longer scroll profiles }\end{array}$ \\
\hline $\begin{array}{l}\text { scroll wall } \\
\text { thickness }\end{array}$ & $\begin{array}{l}\text { - Puff and Kruger } \\
\text { (1992) }\end{array}$ & $\begin{array}{l}\text { - reduced energy efficiency } \\
\text { ratio for increasing } t\end{array}$ \\
\hline $\begin{array}{l}\text { built-in } \\
\text { volume ratio }\end{array}$ & $\begin{array}{l}\text { - Chang et al. } \\
\text { (2014,2015) }\end{array}$ & $\begin{array}{l}\text { - higher pressure ratios due } \\
\text { to higher built-in volume ratios }\end{array}$ \\
\hline
\end{tabular}

Base circle radius (a):

Ishii et al. $(1992,1994,1996)$ [77-79] analysed the mechanical efficiency $\left(\eta_{\text {mech }}\right)$ of a scroll compressor which was determined by the ratio of the analytically calculated gas power due to the compression process and the motor input power which is needed to drive the scroll compressor. The deviation from the ideal performance due to friction losses was obtained by multiplying the forces acting on the orbiting scroll, thrust bearing, crank journal and crank pin 
with frictional coefficients respectively. Typical values for the maximum achievable mechanical efficiency are $90-95 \%$. In order to keep suction volume, scroll profile length and scroll wall thickness constant, the base circle radius was increased for a decreasing scroll height or vice versa. The friction losses increased for lower base circle radius values due to the associated increase of the scroll height. A base circle radius of $2.7 \mathrm{~mm}$ and a scroll height of $5 \mathrm{~mm}$ were found as the optimum combination to achieve a maximum mechanical efficiency of $92.5 \%$. It was also shown that increasing crankshaft speed fluctuation ratio (1-4\%), specified as the difference between the maximum and minimum crankshaft rotational speed divided by the average crankshaft rotational speed, generated higher vibrations for higher base circle radius values.

In the analysis of Puff and Kruger (1992) [80], the increasing base circle radius produced a reduction of the mechanical efficiency due to the entire scroll geometry and its eccentricity being simultaneously enlarged, leading to increased friction between the scrolls.

Inner and outer involute initial angles $\left(\alpha_{i}\right.$ and $\left.\alpha_{o}\right)$ :

The involute initial angles were identified as one of the most important parameters in the work of Etemad and Nieter (1989) [81], because they define the size of the discharge port in a scroll compressor or the suction port in a scroll expander respectively. Their results reported a decreasing influence of increasing outer involute initial angles along with increasing scroll heigths on the discharge velocity in a scroll compressor. The capacity, built-in volume ratio and scroll wall thickness were kept constant.

Scroll profile height $(h)$ :

A number of researchers carried out investigations varying the scroll profile height of scroll machines [58,77-83]. The scroll wall thickness, displacement and operating conditions were kept constant to find the optimum scroll geometry in their studies. The evaluation of Morishita and Sugihara (1986) [82] showed that the overturning moment of the moving scroll limited the scroll height. The minimum scroll height was dependent on the weight and outer diameter of the moving scroll. Ishii et al. (1992, 1994, 1996) [77-79] and Etemad and Nieter (1989) [81] pointed out that a larger scroll height also resulted in larger gas forces and therefore increasing shaft loads at the crankshaft and its journal bearings. A lower scroll height resulted in increasing thrust loads from the orbiting scroll which are transmitted to the thrust bearings [77-79,83]. The results of Etemad and Nieter (1989) [81] reported that the flank leakages increased for a higher scroll height whereas the influence of the radial leakages decreased, although the latter still affected the performance more significantly. The analysis of Puff and Kruger (1992) [80] and VanderKooy (2004) [83] also showed that an increase of the scroll height reduced the volumetric efficiency due to the increasing flank leakages. The scroll compressor geometry in the analytical investigations of Zhu et al. (1994) [58] is created by an involute of a circle consisting of a decreased scroll profile height in the discharge chamber in comparison to the suction and expansion chambers. In other words, the built-in volume ratio was increased in order to develop a compressor for higher pressure ratios than in previous studies. But no performance comparison to a conventional constant wall thickness scroll compressor was included in their work. Kawano and Terauchi [84,85] from Sanden Corporation (1984) filed patents for constant wall thickness scroll compressor made of varying scroll heights throughout the working chambers. The studies of Tateishi et al. (2006) [86] and Kuwahara et al. (2017) [87] from Mitsubishi Heavy Industries, Ltd. revealed an improvement of the efficiency by $5.5 \%$ and a significant higher refrigerating capacity of $11 \%$ for this specific $3 \mathrm{D}$ scroll type in comparison to conventional designs due to its smaller size with less clearances leading to less leakages during the compression process. But no details about the built-in volume ratios, the working fluid and the applied pressure ratios were provided. The thicker wall thickness of the end plates of the fixed and orbiting scroll in the regions where the scroll heights are decreased might lead to unbalanced gas forces disadvantaging the driving torque. Moreover, the continuously compression process might be disrupted at the steps where the scroll height is varying due to potential pressure imbalances and the generation of secondary flow vortices.

\section{$\underline{\text { Scroll profile length: }}$}

In 2012, Clemente et al. [88] modelled the performance of two scroll machines numerically by increasing the scroll profile length from 2.75 revolutions to 4.75 . The scroll efficiency was equal to the product of the efficiencies determined by the sub-models incorporating over- and underexpansion, heat transfer, friction and leakage losses respectively. The short scroll reached the maximum scroll efficiency of $70 \%$ at an pressure ratio of 3.5 whereas the long scroll achieved $65 \%$ at 5.5. The lower scroll efficiency of the longer scroll was attributed to excessive heat transfer losses. A scroll profile length of 4.75 revolutions can be also found in the work of and Kane et al. [89] and Manzagol et al. [90]. 
The studies of Puff and Kruger [80] revealed a reduced energy efficiency ratio, which is defined as cooling capacity divided by power input to the scroll compressor shaft, for an increasing wall thickness. The scroll height was increased at the same time to keep the displacement constant.

Built-in volume ratio $\left(r_{v}\right)$ :

The built-in volume ratio $\left(r_{v}\right)$ is specified as the discharge chamber volume at the beginning of the discharge process $\left(V_{d}\right)$ divided by the maximum suction chamber volume $\left(V_{s, \max }\right)$ and reads

$$
r_{v}=\frac{V_{d}}{V_{s, \max }}
$$

Some researchers defined the built-in volume ratio as the expansion chamber volume at the end of the expansion process divided by the expansion chamber volume at the start of the process, but in fact they are identical as the volumes are the same. Each scroll machine has therefore a fixed value for the built-in volume ratio and the size can only be changed permanently by the geometrical variation of the parameters listed above. For instance by increasing the scroll profile length.

Three open-drive scroll expanders with different built-in volume ratios of 2.12, 2.95 and 4.05 were tested by Chang et al. (2014,2015) [91,92] and their experiments revealed maximum isentropic efficiencies of $68.4 \%, 76 \%$ and $73.1 \%$ respectively. As also shown by Clemente et al. [88], a shift towards higher pressure ratios along with increasing built-in volume ratios to reach the maximum isentropic efficiencies can be seen. The $\mathrm{p}-\mathrm{V}$ diagram for the process shows an enhancement of the produced shaft power for an increasing built-in volume ratio. In particular, for Chang et al.'s scrolls, the power achieved was $1.34 \mathrm{~kW}, 1.43 \mathrm{~kW}$ and $2.3 \mathrm{~kW}$.

To sum up this part of the literature survey, it can be stated that among all the geometrical parameters the built-in volume ratio is one of the most important design parameters to predict the expander performance. But the increase of the built-in volume ratio associated with the extension of the scroll profile length is limited, because a longer scroll profile length results in larger radial leakages and increasing heat transfer effects and friction losses. In the following section, the impact of operational parameters on the expander performance of scroll machines with fixed built-in volume ratios is discussed.

Table 2: Scroll machines with different built-in volume ratios

\begin{tabular}{|c|c|c|c|c|c|c|}
\hline Authors & $\begin{array}{l}\text { Built-in } \\
\text { volume ratio }\end{array}$ & $\begin{array}{l}\text { Ideal pressure } \\
\text { ratio }\end{array}$ & $\begin{array}{l}\text { Isentropic } \\
\text { efficiency }\end{array}$ & $\begin{array}{l}\text { Cycle } \\
\text { efficiency }\end{array}$ & $\begin{array}{l}\text { Maximum } \\
\text { shaft power }\end{array}$ & $\begin{array}{l}\text { Working } \\
\text { fluid }\end{array}$ \\
\hline Bell et al. (2011) [51] & 1.61 & - & $65 \%$ & - & - & R410a \\
\hline Hugenroth et al. (2006) [93] & 1.8 & - & $66 \%$ & - & - & R134a \\
\hline Woodland et al. (2012) [94] & 1.8 & 2.1 & $74 \%$ & - & - & R134a \\
\hline Mendoza et al. (2014) $[95,96]$ & 1.9 & $2.2 / 1.95$ & $60 \% / 61 \%$ & - & $0.35 k W / 0.96 k W$ & Air $/ \mathrm{NH}_{3}$ \\
\hline Miao et al. (2017) [97] & 2.27 & - & - & $5.64 \%$ & $2.65 \mathrm{~kW}$ & R123 \\
\hline Kane et al. (2003) [98] & 2.3 & 2.76 & $68 \%$ & $14.1 \%$ & $10 \mathrm{~kW}$ & R134a/R123 \\
\hline Zanelli and Favrat (1994) [12] & 2.44 & 3.2 & $65 \%$ & - & $3.5 \mathrm{~kW}$ & R134a \\
\hline Wang et al. (2009) [27] & 2.5 & 3.7 & $77 \%$ & - & $1 \mathrm{~kW}$ & R134a \\
\hline Lemort et al. (2012) [99] & 3.0 & 3.65 & $71.03 \%$ & - & $2.032 \mathrm{~kW}$ & R245a \\
\hline Yang et al. $(2015,2016)[100,101]$ & - & 3.7 & $75.2 \%$ & $5.4 \%$ & $2.158 \mathrm{~kW}$ & R123 \\
\hline Feng et al. (2017) [102] & 3.0 & - & $85.17 \%$ & $5.14 \%$ & $2.78 \mathrm{~kW}$ & R123 \\
\hline Yanagisawa et al. (2001) [103] & 3.18 & 5.05 & $60 \%$ & - & - & Air \\
\hline Liu et al. (2010) [104] & - & 3.66 & $65 \%$ & - & $1.073 \mathrm{~kW}$ & Air \\
\hline Yang et al. (2017) [105] & 3.24 & - & $79.56 \%$ & $5.92 \%$ & $2.64 \mathrm{~kW}$ & R245fa \\
\hline Gao et al. (2015) [106] & - & 5.0 & $70 \%$ & - & $0.31 \mathrm{~kW}$ & Air \\
\hline Qiu et al. (2018) [107] & 3.5 & - & $58 \%$ & - & $0.965 \mathrm{~kW}$ & Air \\
\hline Declaye et al. (2013) [108] & 3.95 & $3.42 / 4.33$ & $75.7 \%$ & $8.5 \%$ & $2.1 \mathrm{~kW}$ & $\mathrm{R} 245 \mathrm{a}$ \\
\hline Lemort et al. (2009) [13] & 4.05 & 5.25 & $68 \%$ & - & $1.82 \mathrm{~kW}$ & R123 \\
\hline Peterson et al. (2008) [109] & 4.57 & 3.82 & $50 \%$ & $7.2 \%$ & $0.256 \mathrm{~kW}$ & R123 \\
\hline
\end{tabular}

\subsection{Influence of the built-in volume ratio on the expander performance}

As already mentioned in the previous section, the built-in volume ratio is one of the most important parameters from the thermodynamic point of view that affects the performance of a scroll expander. Further important fluid parameters 
are the inlet and outlet pressure which are defined by the pressure ratio. The matching of the imposed pressure ratio and the built-in volume ratio is essential in order to avoid under- or over-expansion losses. Along with other influencing factors such as the rotational speed, leakage flows, friction and heat transfer losses, this adjustment is important to achieve an efficient performance. Fig.5 [76] illustrates the pressure-volume diagram of the under-expansion (a) and over-expansion (b) phenomena. The sections A-B, B-C and C-D-E represent the suction, expansion and discharge process respectively. $p_{h}$ is specified as the inlet pressure, $p_{x}$ as the pressure at the end of the expansion process and $p_{a}$ as the outlet pressure. $\epsilon^{*}$ and $\epsilon$ are defined as the real and designed pressure ratio respectively. A pressure gradient characterised by a higher pressure in the expansion chambers at the time when the expansion process is finished than that in the expander outlet pipe leads to under-expansion losses. The energy of the working fluid can not be fully expanded. In contrast to over-expansion losses which are associated with a back flowing working fluid during the discharge process. This is induced by a pressure gradient characterised by a higher pressure in the expander outlet pipe compared to that in the expansion chambers. Over-expansion losses are particularly detrimental to the scroll expander efficiency.

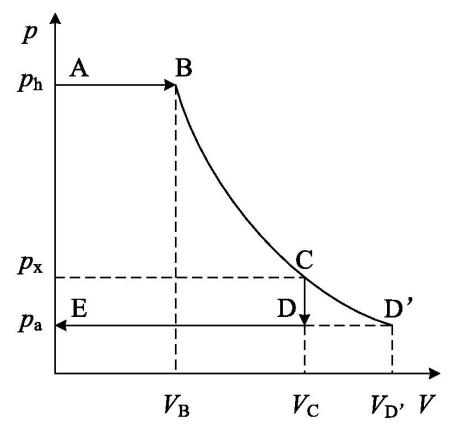

(a) $\varepsilon^{*}>\varepsilon$

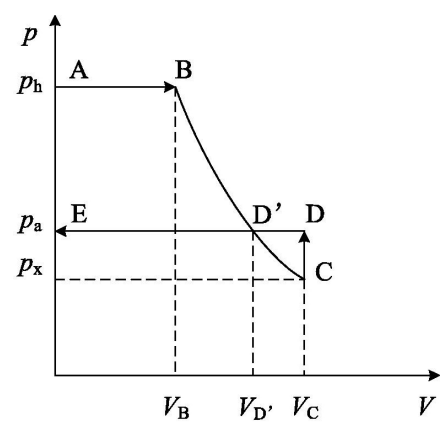

(b) $\varepsilon^{*}<\varepsilon$

Figure 5: Under-expansion (a) and over-expansion (b) [76]

The present section considers experimental investigations of constant wall thickness (excluding the scroll tip area) scroll expanders and compressors in the order of increasing built-in volume ratios as shown in Tab.2. Note that in each of the studies considered in this section, the value for the built-in volume ratio was not varied. In other words, the scroll machines had a fixed built-in volume ratio throughout each investigation.

The test rigs in most of the cited papers were only developed to investigate the scroll expander performance itself and not the system performance of the entire cycle. Hence, no detailed discussion of the influence of the scroll expander performance on the thermal cycle efficiency are included in this section. The few available values were listed in Tab.2. In general, the thermal cycle efficiency is specified as the ratio between the net work produced by the cycle and the heat supply to the working fluid and reads

$$
\eta_{\text {cycle }}=\frac{\dot{W}_{\text {Net }}}{\dot{Q}_{\text {Supply }}}=\frac{\dot{W}_{\text {Expander }}-\dot{W}_{\text {Pump }}}{\dot{Q}_{\text {Supply }}}
$$

The net work is determined by the difference of the produced power output of the scroll expander and the power used to drive the pump of the cycle.

Low built-in volume ratio $(<2.0)$

In 2012, Woodland et al. [94] carried out experimental studies of an off-the-shelf automotive A/C scroll compressor working as an expander in an ORC with R134a. Although Bell et al. [51] and Hugenroth et al. [93] carried out their investigations on the same machine in a Liquid-Flooded Ericsson Cycle (LFEC) application, two different values for the built-in volume ratio were specified in each case. The former determined their value of 1.61 through scroll profile coordinate measurements whereas the latter provided no details how they determined their value of 1.8 , but only assumed the scroll expander built-in volume ratio to be 1.8 [94]. Their results revealed that the maximum isentropic efficiency was achieved at an pressure ratio which was slightly higher than the value of the built-in volume ratio. This is consistent with the findings of Lemort et al. [13]. In addition, it can be noted that over-expansion had more adverse effects on the performance than under-expansion.

Mendoza et al. (2014) [95,96] integrated a scroll expander with a built-in volume ratio of 1.9 into an experimental test rig fed by air and ammonia. An increasing pressure ratio yield a significantly higher isentropic efficiency for both 
fluids reaching peak values of $60 \%$ and $61 \%$ at a pressure ratio being higher than the built-in volume ratio. The power output also increased for an increasing rotational speed and maximum values of $354 \mathrm{~W}$ and $958 \mathrm{~W}$ for air and ammonia has been revealed respectively. Their particular purpose was to make it suitable for absorption power and cooling cycles which has been successfully proven. Studies on scroll expander implemented in this cogeneration cycle can be also found in the work of Demirkaya et al. (2011) [110]. Ammonia vapor at superheated conditions improved the cycle efficiency at the expense of lower cooling outputs. For the use of ammonia instead of air, Ingley et al. (2005) [111] claimed that the number of scroll chambers needs to be increased to lower the effects of leakages which were responsible for the low isentropic efficiency of $18.2 \%$ at a rotational speed of $2000 \mathrm{rpm}$ and an inlet pressure of $5.52 \mathrm{bar}$ in their experimental studies of a scroll expander fed by air. No commercial solutions of these low built-in volume ratio scroll expander can be found in the literature.

Medium built-in volume ratio (2.0-3.0)

The maximum shaft power of $2.65 \mathrm{~kW}$ along with the thermal ORC cycle efficiency of $5.64 \%$ was achieved with a scroll expander characterised by a built-in volume ratio of 2.27 in the experimental work of Miao et al. (2017) [97]. It can be noted that a larger heat transfer area of the evaporator is necessary to maintain the degree of superheat of the working fluid at the scroll expander suction port which in turn would lead to the opportunity to impose higher mass flow rates to the expander. With the aid of the experimental data, they developed an ORC model including a semi-empirical scroll expander model which was enhanced by predicting the complex flow and heat transfer processes based on the structure parameters of the scroll expander geometry. Hence, less empirical coefficients were necessary compared to previous work. A power output of $5.08 \mathrm{~kW}$ and a thermal cycle efficiency of $10.42 \%$ has been predicted for a larger built-in volume ratio of 6 .

Kane et al. (2003) [98] applied combined topping and bottoming ORCs to a hybrid solar thermal power plant using R134a and R123 as the working fluids respectively. The system was equipped with two hermetic lubricated scroll expanders with the built-in volume ratios of 2.3. With an applied pressure ratio range between 1.6 and 4.8 the electric power produced varied between 3 and 10kW. A peak isentropic efficiency of $68 \%$ was achieved at an imposed pressure ratio which was 1.2 times the built-in volume ratio as illustrated in Fig.6. Eneftech Innovation [31] (2013) developed commercial scroll expander to recover waste heat from engine exhaust gases and industrial applications in accordance to Kane et al.'s work. Air Squared, Inc. [30] provides a commercial scroll expander characterised by a built-in volume ratio of 2 for lubricated or oil-free expansion of refrigerants.

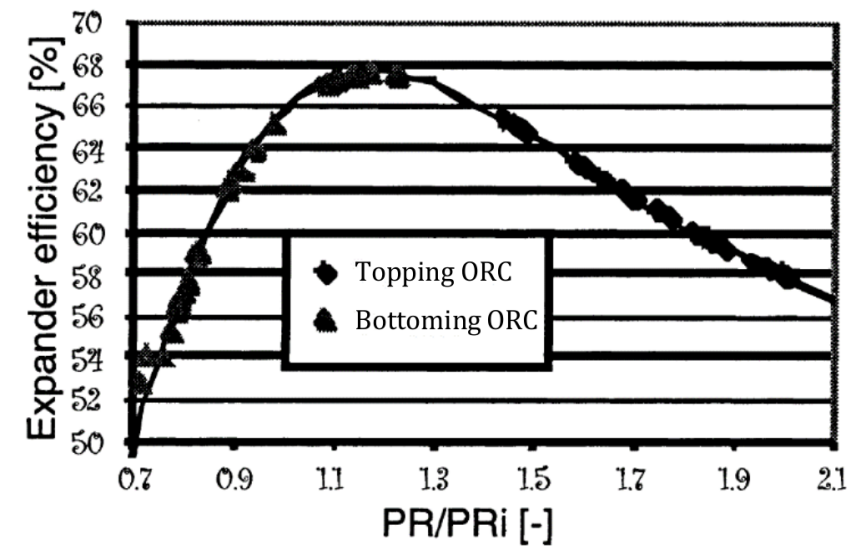

Figure 6: Variation of isentropic efficiency with pressure ratio [98]

Experimental work on a hermetic lubricated scroll expander fed with refrigerant R134a was conducted by Zanelli and Favrat (1994) [12]. The original compressor was characterised by a built-in volume ratio of 2.44 . A maximum overall isentropic efficiency of $65 \%$ was reported for a rotational speed of $3000 \mathrm{rpm}$ and a pressure ratio of 3.2 which is a factor of about 1.3 higher than the built-in volume ratio. The results also exhibited a linear increase of the electric power with increasing pressure ratio. A maximum power output of $3.5 \mathrm{~kW}$ was reported.

Wang et al. (2009) [27] conducted an experimental performance of a compliant scroll expander with a built-in volume ratio of 2.5 for an ORC. To seal the fixed and orbiting scroll axially and to prevent leakage, lubricant at high pressure was used to generate an external controlled sealing pressure involving an axial force on top of the upper fixed scroll through a sealed piston assembly. The isentropic efficiency remained stable for rotational speeds from 2500 to 
$3600 \mathrm{rpm}$ and over pressure ratios from 2.65 to 4.84 . A peak isentropic efficiency of $77 \%$ and a maximum shaft power of $1 \mathrm{~kW}$ were reached. No further investigations of this system can be found in the literature.

Lemort et al. (2012) [99] built a micro-scale ORC system including a hermetic scroll expander with a built-in volume ratio of 3.0. An overall isentropic efficiency of $71.03 \%$ and a maximum electrical power output of $2.032 \mathrm{~kW}$ were measured for the scroll expander working with R245fa. The investigation revealed that over-expansion losses were responsible for a decrease of the isentropic efficiency at small pressure ratios. Moreover, the peak in isentropic efficiency occurred at an pressure ratio between 3 and 4.5.

For a small-scale ORC system equipped with a given scroll expander geometry, Yang et al. (2015) [100] proposed to control the pump rotational speed and the expander torque by means of an AC motor to regulate the scroll expander inlet conditions affecting the ORC system performance. Their experimental studies pointed out that a vapour superheating of $13^{\circ} \mathrm{C}$ is essential for the complete vaporisation of liquid droplets before the fluid is inserted into the expander suction port. These new findings were in contrast to previous work which required saturation vapor conditions at the scroll expander inlet to reach the optimum performance. The system net power output of $1.881 \mathrm{~kW}$ included the pump consumption and resulted in a thermal cycle efficiency of $5.33 \%$ at the optimum expander torque of $15.51 \mathrm{Nm}$ and a pump speed of 480rpm. In another work, Yang et al. (2016) [101] emphasised that the ORC system performance is strongly related to the heat source and environmental temperature which can be captured by the non-dimensional integration temperature difference $\left(\Delta T_{i, s}^{*}\right)$. It enables the better optimisation of the enthalpy difference defining the applied pressure ratio to the expander. Their experimental verification yield an optimum scroll expander power output of $2.158 \mathrm{~kW}$ and isentropic and thermal cycle efficiencies of $75.2 \%$ and $5.4 \%$ respectively at $\Delta$ $T_{i, s}^{*}$ of 0.282 representing the heat source temperature of $140^{\circ} \mathrm{C}$. The vapor cavitation in the expansion device was diminished due the reached vapor superheating of $12.7^{\circ} \mathrm{C}$.

In contrast to many other researchers, Feng et al. (2017) [102] investigated the performance of all four key components such as scroll expander (built-in volume ratio: 3.0), pump, evaporator and condenser and their influence on the overall ORC system performance. An increasing mass flow rate massively increased the expander isentropic efficiency reaching a peak of $85.17 \%$. The latter was not improved for an increasing heat source temperature, whereas the performance of all key components was enhanced leading to a maximum thermal cycle efficiency of $5.14 \%$.

High built-in volume ratio $(>3.0)$

Yanagisawa et al. (2001) [103] studied an oil-free scroll type expander with a built-in volume ratio of 3.18 driven by compressed air. The maximum achieved isentropic efficiency was $60 \%$ for the built-in volume ratio of 5.05 and a rotational speed of 2500rpm. As indicated in the evaluation, leakages mainly affected the performance at a lower rotational speed. Mechanical losses were figured out to be the main influence on the performance for higher rotational speeds. The pressure decrease during the expansion showed the behaviour of a polytropic process.

Liu et al. (2010) [104] manufactured a scroll expander prototype and carried out an experimental validation of their mathematical model which also considered suction and discharge pressure losses compared to previous work. An isentropic efficiency of $65 \%$ and a power output of $1.073 \mathrm{~kW}$ at a pressure ratio of 3.66 were achieved in the experimental studies. Manufacturing inaccuracies of the expander prototype and leakages a high and low rotational speeds lead to the relative low efficiency and the mismatch of $8.6 \%$ between the simulations and the experiments. Zhang et al. (2017) [76] also validated their scroll expander thermodynamic model by means of air as the working fluid. Their studies yield an experimental power output of $1.2 \mathrm{~kW}$ whereas the isentropic efficiency was just $30.5 \%$ which was due to the high leakages at the relative low selected rotational speed of $1200 \mathrm{rpm}$.

Gao et al. (2015) developed thermodynamic and heat transfer models for ORC systems driven by R245fa on the basis of the experimentally determined performance data of a scroll expander with a displacement of $66 \mathrm{ml} / \mathrm{r}$ fed by air. The isentropic efficiency varied in the range of $62-70 \%$ by increasing the inlet pressure and the rotational speed simultaneously resulting in less leakages. Qiu et al. (2018) [107] examined the suitability of a scroll compressor driven in reverse as expander for the integration in a small scale ORC unit by conducting preliminary experiments using air as the working fluid. It can be noted that a higher power output was generated for higher rotational speeds leading to a higher adiabatic efficiency as a result of lower leakages. The numerical simulations of an ORC system fed by R134 and based on the geometrical and experimental data yield a cycle efficiency of $5.3 \%$ and the need for higher built-in volume ratio of the expander to further improve the thermal efficiency of the system.

The experimental studies of Yang et al. (2017) [105] revealed an improved ORC system performance for an increasing pressure drop which is specified as the difference between the inlet pressure of the scroll expander (built-in volume ratio: 3.24) and the pump. The optimum pressure drop was found to be 8.16bar. Increasing values are also associated with increasing mass flow rates leading to a maximum shaft power, isentropic efficiency and thermal cycle 
efficiency of $2.64 \mathrm{~kW}, 79.59 \%$ and $5.92 \%$ respectively.

In 2013, Declaye et al. [108] experimentally tested an ORC equipped with an open-drive oil-free scroll expander fed by R245fa. The built-in volume ratio was 3.95. Because of the low friction losses, a maximum isentropic efficiency of $75.7 \%$ was accomplished and the maximum delivered power was $2.1 \mathrm{~kW}$. The applied pressure ratio to achieve the maximum isentropic efficiency varied from 3.42 for the rotational speed of 2000rpm and 4.33 for $3500 \mathrm{rpm}$. The relocation of the maximum position was mainly influenced by mechanical losses and inlet pressure drop at higher rotational speeds, and by leakages at low rotating speeds and high pressure ratios. An increasing shaft power with an increasing pressure ratio can be noted from the analysis due to the higher density of the the working fluid at higher pressure.

Lemort et al. [13] conducted an experimental investigation on an open-drive oil-free scroll expander operating with R123 and integrated into an ORC. The scroll machine with a built-in volume ratio of 4.05 reached an overall isentropic efficiency of $68 \%$. A maximum shaft power of $1.82 \mathrm{~kW}$ was delivered. The isentropic efficiency declined extremely at low pressure ratios due to over-expansion losses.

The experimental investigation presented in the paper from Peterson et al. [109] showed that the scroll expander with a built-in volume ratio of 4.57 and driven by $\mathrm{R} 123$ revealed a maximum generated capacity of $256 \mathrm{~W}$ and a maximum isentropic efficiency of $50 \%$ at an pressure ratio of 3.82 and a rotational speed of $1287 \mathrm{rpm}$. It can be seen that the imposed pressure ratio is lower than the built-in volume ratio. To avoid the excessive leakage in their scroll expander characterised by a kinematically rigid configuration, the authors suggested the use of a compliant scroll device for future investigations.

The product portfolio of Air Squared, Inc. [30] includes commercial scroll expander characterised by built-in volume ratios of 3.5 and up to 5.7. A power output between $1 \mathrm{~kW}$ and $10 \mathrm{~kW}$ can be produced depending on different displacements per revolution. Scroll expander consisting of a cast iron construction are also offered, especially for high-temperature and high-pressure operation.

In summary, it can be said that higher built-in volume ratios are required for efficient operation of scroll expander with a constant wall thickness at higher pressure ratios. The peak isentropic efficiency was achieved at a pressure ratio which is slightly higher than the built-in volume ratio, which in turn can produce an increased shaft power since the inlet pressure and density are higher which causes a higher mass flow rate in the scroll machine. So it turns out clearly that there is a significant interest in development of high pressure ratio expanders with a built-in volume ratio of higher than 3. Furthermore, a high pressure ratio along with a sufficient heat source temperature is particularly favourable for the overall efficiency of ORC systems. But apart from a few manufacturers who developed commercial scroll expander with high built-in volume ratios, almost all the published research in this section was carried out on scroll compressor which have been modified and driven in reverse. It can be noted that experimental studies of scroll machines driven by compressed air are a promising tool for assessing the suitability of scroll expander for ORC systems and other power cycle.

\section{Scroll expander with a variable wall thickness}

It is of interest to consider if the scroll expander geometry design can be changed by varying the wall thickness in order to find a better and more efficient scroll expander geometry for high pressure ratios. In the 1990s, researchers started to develop equations to describe alternative scroll geometries and designed geometrical models to investigate the working process. Tab.3 provides an overview of different geometry approaches for scroll geometries with variable wall thicknesses.

Bush and Beagle $(1992,1994)[112,113]$ provided a general relationship to generate scroll profiles of almost any form. Compared to a scroll geometry using an involute of a circle (Fig.7a), the scroll profile length (Fig.7b) was reduced from 5.5 revolutions to 2.5 revolutions by varying the wall thickness whereas the built-in volume ratio of 5.6 remained the same. The benefits may include reduced overall tip leakage area, a shorter residence time of the gas in the machine with less time for tip leakage and detrimental heat transfer. The drawbacks might be the variation of driving torque and gas forces in the compression process. A few researchers have investigated Bush and Beagle's proposed geometry [114-117]. Scrolls created by involute of circles with constant and variable wall thicknesses can be analysed in terms of asymmetric radial and tangential gas pressure forces, asymmetries in the chamber volumes and non-uniform start-of-suction crank angles by means of the developed thermodynamic model of Gagne and Nieter (1996) [114]. But their validation has only been carried out against experimental data of a constant wall thickness scroll compressor. By tapering both scrolls toward the outside, scrolls with variable wall thicknesses as proposed by Bush and Beagle (1992) [112] can be generated with the Milling Tool Method of Lindsay and Radermacher (2000) [115]. 
Table 3: Scroll geometries made of variable wall thicknesses

\begin{tabular}{|c|c|c|}
\hline $\begin{array}{l}\text { Geometry } \\
\text { approach of }\end{array}$ & Author & Method \\
\hline $\begin{array}{l}\text { Bush and } \\
\text { Beagle }\end{array}$ & $\begin{array}{l}\text { - Bush and Beagle } \\
\text { (1992,1994) } \\
\text { - Gagne and Nieter } \\
\text { (1996) } \\
\text { - Lindsay and } \\
\text { Radermacher } \\
\text { (2000) } \\
\text { - Rak et al. } \\
(2014)\end{array}$ & $\begin{array}{l}\text { - theoretical } \\
\text { investigations } \\
\text { - simulation } \\
\text { program } \\
\text { - simulation } \\
\text { program } \\
\text { - CFD }\end{array}$ \\
\hline Tojo et al. & $\begin{array}{l}\text { - Tojo et al. } \\
(1995) \\
\text { - Liu et al. } \\
\quad(2010,2012)\end{array}$ & $\begin{array}{l}\text { - concept } \\
\text { (patent) } \\
\text { - geometric and } \\
\text { FEM model }\end{array}$ \\
\hline $\begin{array}{l}\text { Gravesen and } \\
\text { Henriksen }\end{array}$ & $\begin{array}{l}\text { - Gravesen and Henriksen } \\
(1998,2001) \\
\text { - Shaffer and Groll } \\
(2012,2013) \\
\text { - Dickes } \\
(2013)\end{array}$ & $\begin{array}{l}\text { - theoretical } \\
\text { equations } \\
\text { - geometric model } \\
\text { including scroll tip } \\
\text { - deterministic } \\
\text { model }\end{array}$ \\
\hline Bin et al. & $\begin{array}{l}-\operatorname{Bin} \text { et al. } \\
(2016)\end{array}$ & $\begin{array}{l}\text { - thermodynamic } \\
\text { model }\end{array}$ \\
\hline
\end{tabular}

(a) constant wall thickness

(b) variable wall thickness

Figure 7: Scroll profiles with the same built-in volume ratio [112]

The CFD simulations of Rak et al. (2014) [116,117] revealed that the wall heat transfer coefficient in the chamber of a scroll geometry proposed by Bush et al. [112] was up to three times larger compared to a scroll geometry with a constant wall thickness. A decreased temperature in all working chambers and in the scrolls was achieved with an internal cooling system. Based on the CFD findings, the development of a highly efficient scroll compressor for cryogenic applications was planned to be carried out.

Liu et al. $(2010,2012)[118,119]$ used the geometry approach of Tojo et al. [120] to develop a geometrical and FEM model for a variable wall thickness scroll compressor. Their studies revealed a better strength and rigidity for the latter in comparison to a constant wall thickness scroll expander. The suction volume, volume ratio and housing size were kept constant in both cases. It is also stated that better reliability and higher efficiency can be achieved and higher operating pressures could be applied to variable wall thickness scrolls.

Gravesen and Henriksen $(1998,2001)$ [64,121] developed an 8-dimensional planar curve frame for the generation and optimisation of scroll geometries. A pair of scrolls was defined by an intrinsic equation consisting of five scalar coefficients, the scroll profile length, the radius of circular motion and a scalar length. This allowed the design of scroll profiles with variable wall thicknesses and calculation of all geometrical quantities in a closed analytical form. Examples of these different designs are shown in Fig.8. Shaffer and Groll $(2012,2013)$ [122,123] generated further scroll geometries with the parametric representation introduced by Gravesen and Henriksen (2001) [64]. First order, first order with offset, second and third order scroll curves were obtained and a variety of different scroll involute geometries consisting of constant or variable wall thicknesses can be defined with their analytical solution. Dickes (2013) [124] applied the frame given by Gravesen and Henriksen [64] to create the geometry of a two-stage/single-shaft scroll expander with a decreasing wall thickness. The predicted isentropic efficiency increased by $6.2 \%$ in comparison to a scroll machine consisting of two Copeland scroll expanders in series with a constant wall thickness. 


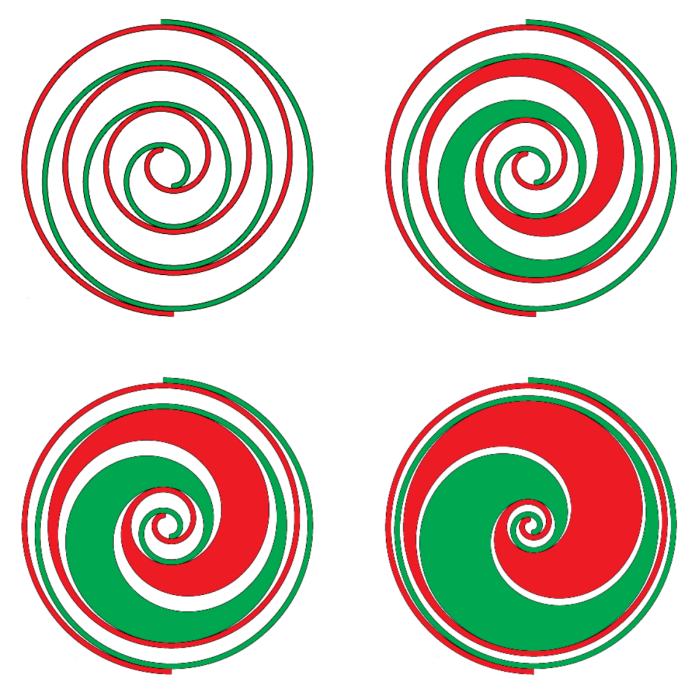

Figure 8: Scroll profiles with variable wall thicknesses [64]

Bin et al. (2016) $[125,126]$ developed a thermodynamic model for a variable wall thickness scroll compressor generated by combining a circle of involute, high order curve and non-working arc. The model was successfully validated against measurements and showed a good accuracy for the output power, mass flow rate and discharge temperature.

In summary, the literature for scroll machines with variable wall thicknesses is mainly limited to theoretical works since the research and development of these scroll machine designs is still at an early stage. Apart from the manufactured single-stage scroll expander prototype of Dickes (2013) [124] and Bin et al.'s (2016) [125, 126] variable wall thickness scroll compressor for the purpose of validation, no further experimental studies can be found in the literature. Considering the possible benefits of less overall leakage areas, shorter residence time of the gas and less time for leakages and heat transfer, the scroll machine with variable wall thicknesses could be a promising candidate to further improve the efficiency and power output in an ORC system when high pressure ratio is preferred. It has also the opportunity of opening up new application fields such as refrigeration cycles and other power cycles in which high pressure ratios are needed. In contrast, the potential disadvantages of the more complex variable wall thickness scroll geometry may be a reduced volume flow rate. It may also decrease the suction chamber volume due to the additional occupied space of the variable wall thickness scroll profiles contributing to a lower mass flow rate at the expander inlet. Hence, the increase of the inlet pressure which is necessary to apply higher pressure ratios could be prevented. Or seen from another perspective, the entire scroll geometry and its eccentricity may need to be simultaneously enlarged to maintain the suction chamber volume leading to an even larger size than conventional designs. Furthermore, the benefit of applying higher pressure ratios may result in much higher flank leakages diminishing the expander efficiency. Besides that, the lower number of expansion chambers in a variable wall thickness design may generate higher pressure gradients between the individual chambers which could even further contribute to high speed flank leakages. The gas force and driving torque variations and a bad machinability should be also considered since the advanced 3D printing technologies have not achieved the desired level of accuracy yet.

\section{Scroll expander made of unconventional scroll profiles}

Apart from scroll profiles formed by an involute of circle, scroll profiles can be formed with a variety of other geometrical curves. Montelius (1943) [46] used spirals of Archimedes to define the profiles of a rotary compressor or expander. Young and McCullough (1975) [45] filed a patent for a scroll-type positive fluid displacement apparatus created from involute curves combined with circular arcs. Güttinger (1976) [44] designed a displacement machine for compressible media characterised by offset spliced involutes. Muir et al. (1986) [127] developed a scroll-type machine with a rotation controlling mechanism to limit the relative rotation of the scrolls. Tab.4 lists the studies related to geometries made of unconventional scroll profiles.

Li et al. (1996) [128,129] generated three different scroll compressor geometries using involute of circle, square and line segment scroll profiles while keeping the suction volume, built-in volume ratio, scroll height and scroll thickness constant. The most compact scroll compressor design with the least number of working chambers and the shortest scroll profile length was generated by using an involute of a circle scroll profile. The performance tests were carried out for constant operating conditions and the highest driving moment was produced by the circle of involute scroll design. 
Table 4: Scroll geometries made of unconventional scroll profiles

\begin{tabular}{|c|c|c|c|}
\hline Scroll profile & Author & Method & $\begin{array}{l}\text { Objectives / } \\
\text { Results }\end{array}$ \\
\hline $\begin{array}{l}\text { spirals of } \\
\text { Archimedes }\end{array}$ & $\begin{array}{l}\text { Montelius } \\
(1943)\end{array}$ & $\begin{array}{l}\text { concept } \\
\text { (patent) }\end{array}$ & $\begin{array}{l}\text { sealing between } \\
\text { co-operating } \\
\text { spiral surfaces }\end{array}$ \\
\hline $\begin{array}{l}\text { involute } \\
\text { curves with } \\
\text { circular arcs }\end{array}$ & $\begin{array}{l}\text { Young and } \\
\text { McCullough } \\
(1975)\end{array}$ & $\begin{array}{l}\text { concept } \\
\text { (patent) }\end{array}$ & efficient sealing \\
\hline $\begin{array}{l}\text { offset spliced } \\
\text { involutes }\end{array}$ & $\begin{array}{l}\text { Güttinger } \\
(1976)\end{array}$ & $\begin{array}{l}\text { concept } \\
\text { (patent) }\end{array}$ & $\begin{array}{l}\text { improved } \\
\text { construction }\end{array}$ \\
\hline $\begin{array}{l}\text { rotation contr. } \\
\text { mechanism }\end{array}$ & $\begin{array}{l}\text { Muir et al. } \\
(1986)\end{array}$ & $\begin{array}{l}\text { concept } \\
\text { (patent) }\end{array}$ & $\begin{array}{l}\text { limit relative } \\
\text { rotation of } \\
\text { scrolls }\end{array}$ \\
\hline $\begin{array}{l}\text { involute of a circle, } \\
\text { square, line segment } \\
\text { scroll profiles }\end{array}$ & $\begin{array}{l}\text { Li et al. } \\
(1996)\end{array}$ & $\begin{array}{l}\text { analytical } \\
\text { study }\end{array}$ & $\begin{array}{l}\text { highest driving } \\
\text { moment for } \\
\text { involute of a circle }\end{array}$ \\
\hline $\begin{array}{l}\text { regular odd, } \\
\text { segment and } \\
\text { regular even } \\
\text { polygon invol. }\end{array}$ & $\begin{array}{l}\text { Wang et al. } \\
(2005,2010)\end{array}$ & $\begin{array}{l}\text { analytical } \\
\text { study }\end{array}$ & $\begin{array}{l}\text { segment and } \\
\text { regular even } \\
\text { polygon invol. } \\
\text { best choice }\end{array}$ \\
\hline $\begin{array}{l}\text { arc-arc-line } \\
\text { unit profile }\end{array}$ & $\begin{array}{l}\text { Wang } \\
(2010,2011)\end{array}$ & $\begin{array}{l}\text { theoretical/ } \\
\text { experimental }\end{array}$ & increased $P$ \\
\hline \multirow[t]{3}{*}{$\begin{array}{l}\text { twin-spiral } \\
\text { scrolls }\end{array}$} & $\begin{array}{l}\text { Peng et al. } \\
(2008,2012)\end{array}$ & $\mathrm{CAE}$ & $\begin{array}{l}\text { higher built-in } \\
\text { volume ratio } \\
\text { increased } P\end{array}$ \\
\hline & $\begin{array}{l}\text { Qiang et al. } \\
(2010,2013)\end{array}$ & $\begin{array}{l}\text { geom. model, } \\
\text { analytical } \\
\text { study }\end{array}$ & higher displ. \\
\hline & $\begin{array}{l}\text { Qiang et al. } \\
(2013)\end{array}$ & $\begin{array}{l}\text { dynamic model, } \\
\text { experimental }\end{array}$ & $\begin{array}{l}\text { smaller } \eta_{v o l} \\
\text { for multi-spiral } \\
\text { scrolls }\end{array}$ \\
\hline $\begin{array}{l}\text { Co-rotating } \\
\text { scroll machine }\end{array}$ & $\begin{array}{l}\text { Mendoza et al. } \\
(2017)\end{array}$ & $\begin{array}{l}\text { thermodynamic } \\
\text { model, experimental }\end{array}$ & $\begin{array}{l}P_{\text {out }}=1.74 \mathrm{~kW} \\
\eta_{\text {isothermal }}=34 \%\end{array}$ \\
\hline $\begin{array}{l}\text { Quad orbiting } \\
\text { scroll machine }\end{array}$ & McTaggart (2004) & concept & $\begin{array}{l}\text { Lower level of noise } \\
\text { and vibration due to } \\
\text { a better lubrication }\end{array}$ \\
\hline
\end{tabular}

The analytical study of L.Wang et al. $(2005,2010)[130,131]$ revealed that in contrast to regular odd polygon involutes, the segment and regular even polygon involutes can be used for the generation of scroll profiles.

G.Wang $(2010,2011)$ [132-134] analysed the experimental performance of a scroll compressor made of a scroll profile which combines several profile units comprising a big and a small arc and a straight line respectively. A linear increase of mass flow rate and shaft power can be noted for an increasing rotational speed in the lower speed range up to 1800rpm. Whereas the shaft power further increased linearly for higher rotational speeds, the mass flow rate reached its maximum and remained stable. The coefficient of performance (COP), defined as the cooling capacity in relation to the necessary work supplied to the scroll compressor, and the mass flow rate were higher compared to a scroll compressor created by the involute of a circle with a constant wall thickness which had the same scroll height, thickness and plate diameter.

Experimental studies of a co-rotating scroll machine for a compressed air energy storage application were carried out for the first time by Mendoza et al. (2017) [135]. The expansion process in this scroll machine is driven by a pure rotational anticlockwise movement of two interleaving scroll involutes [136-140]. Hence, levels of noise and vibration can be reduced and it can be equipped with two inlet and outlet ports which may lead to reduced suction pressure losses [135]. A maximum shaft power of $1.74 \mathrm{~kW}$ and an overall isothermal efficiency of $34 \%$ was achieved for a scroll machine characterised by the built-in volume ratio of 3.3 and a designed pressure ratio of 4 . Moreover, the opportunity of water injections to reduce internal leakages and to reach a quasi-isothermal expansion process make it not only suitable for ORC systems but also for absorption power and hybrid absorption cycles. In contrast, the potential disadvantage of the complex drive mechanism may lead to a higher unreliability. Besides that, one of the key challenges is the perfect synchronisation of two orbiting scrolls by means of a control unit to ensure a constant clearance between the moving scrolls which is necessary to avoid increasing flank leakages.

The quad orbiting scroll concept is a scroll device equipped with four pairs of orbiting and fixed scrolls which might contribute to lower noise and vibration levels but associated with the potential disadvantage of an elaborate design [141]. In particular, the much higher weight, size, costs, the complex thermal management accompanied with the high demand of lubrication and the need of a shared power transmission mechanism might be the reasons why no further works can be found in the literature. 
Twin-spiral scroll geometry

Peng et al. (2008, 2012) [142,143] used a computer-aided engineering (CAE) tool to investigate the impact of the non-uniform pressure and temperature field on the von Mises stress and deformation of a twin-spiral scroll compressor. Optimum axial $(0.025 \mathrm{~mm})$ and radial $(0.03 \mathrm{~mm})$ sealing gap values were revealed to maximize the efficiency. The orbiting and fixed plate of the latter are consisting of two scroll wraps respectively as illustrated in Fig.9. According to the authors, a higher built-in volume ratio along with a reduced scroll plate diameter can be achieved which results in a more compact design leading to an improved performance and increased power output.

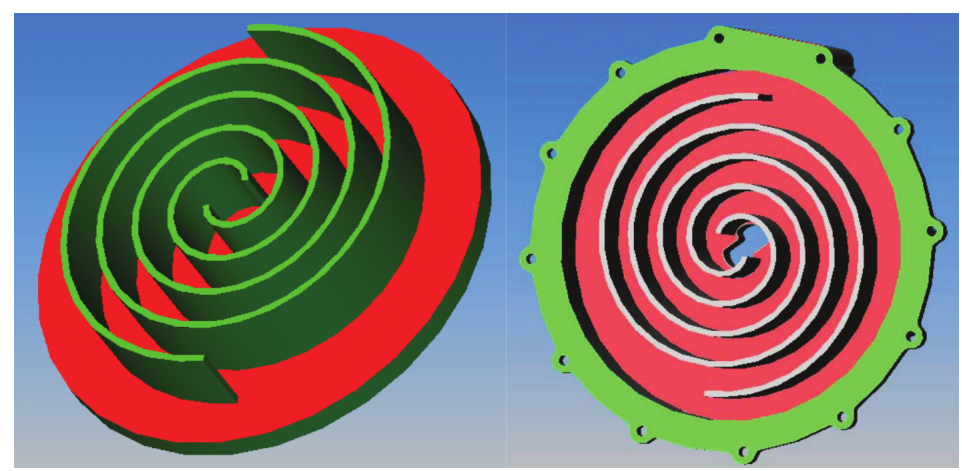

Figure 9: Twin-spiral scroll geometry [142]

Qiang (2010,2013) et al. [144-146] developed a geometrical model and analytically examined scroll machines with an arbitrary number of scrolls on its individual scroll. They claimed that the twin-spiral scroll compressor could achieve a higher isentropic efficiency and a high working pressure ratio compared to a single-spiral scroll compressor [147,148]. The model did not consider the frictional losses. Qiang et al. [149] found that measurements of the power outputs for single- and twin-spiral air scroll compressors were in good agreement with the results of their dynamic model. The volumetric efficiency of a multi-spiral compressor was lower than that of a single-spiral compressor due to the occupied space of the scrolls.

Although the studies of scroll expanders made of unconventional scroll profiles are limited and no commercial solutions are available yet, it appears that the twin-spiral scroll geometry may have the potential to further improve the isentropic efficiency and the power output. It can be a promising candidate to overcome the geometric constraints of a scroll expander generated by an involute of a circle with a constant wall thickness to make it suitable for particular applications. But the possible reduction of the volume flow rate and volumetric efficiency as a result of the occupied space of two scrolls on the fixed and orbiting scroll respectively may disadvantage the twin-spiral scroll machine for ORC systems. Similar to the variable wall thickness design, the accompanying potential reduction of the suction port may outbalance the positive effects of higher built-in volume ratios. Whereas, the increase of the suction port could massively increase the entire geometry associated with higher leakage, friction and heat transfer losses. Besides that, the potential shift to higher pressure ratios may also generate high speed flank leakages. A higher number of scroll on its individual scroll may also lead to sealing and lubrication issues. Moreover, the working process of twin-spiral scroll devices is almost unknown due to the lack of available experimental data.

\section{Scroll tip geometries}

The three most common options to close the scroll curves in the suction area of the scroll expander are shown in Fig.10. Specifically the single arc, dual arc and perfect meshing profile (PMP) scroll tip designs. The scroll tip shape affects the area of the suction chamber and this in turn influences the built-in volume ratio of the scroll expander. Moreover, the geometry of the scroll tip may lead to an impact on the flow rate due to a blockage effect. As a result, a decreased volume ratio can lead to a reduced power output.

Single arc scroll tip design: Blunier et al. (2006,2009) [65,66] developed analytical expressions to connect the scroll starting position of the inner involute and the starting position of the outer involute with a single arc to form the scroll tip geometry which can be either concave or convex.

Dual arc scroll tip design: Hirano et al. (1987) [150] filed a patent for a rotary type fluid machine in which an inside arc having a radius $R$ and a connecting arc having a radius $r$ were connected with a radially outer involute curve and a radially inner involute curve respectively to define the scroll profile.

Perfect meshing profile (PMP): Hirano et al. (1989,1990) [151,152] used a PMP for the scroll tip shape which 
was characterised by two arc curves and a single line to reach a zero clearance volume between two scrolls at the central portion. From a two-dimensional point of view, the two scrolls contact each other either in one point or along a straight-line.

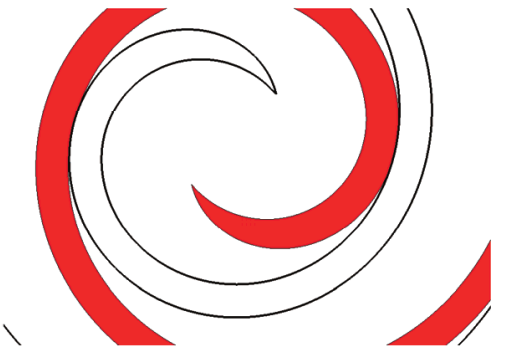

(a) Single arc scroll tip design

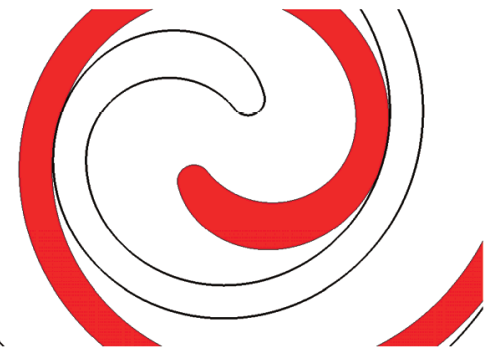

(b) Dual arc scroll tip design

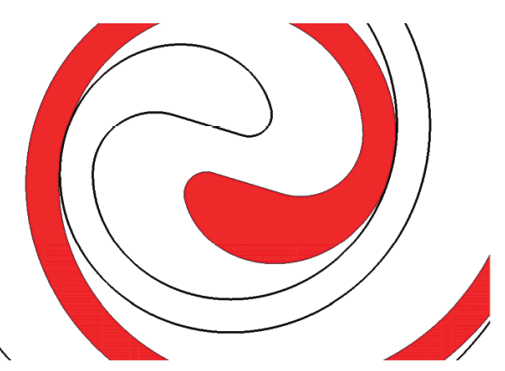

(c) PMP scroll tip design

Figure 10: Scroll tip design variations [153]

There are other options for design of the scroll tips. The plate of the orbiting scroll possessed a discharge slot whereas the fixed scroll possessed a discharge port in the work of Zhu et al. (1994) [58]. This design led to an increased built-in volume ratio with the possibility of application at higher pressure ratio. Liu and Peng (2008) [154] developed geometric models for scroll compressors with symmetrical and asymmetrical scroll tip designs. In symmetrical designs the two scroll tip shapes of the fixed and orbiting scroll have identical shape. In asymmetrical designs the scroll tip shape of the orbiting scroll was thicker than that of the fixed scroll. A smaller volume ratio was achieved for the asymmetric scroll tip design. Tab.5 lists the references to scroll tip geometries found in the literature.

Table 5: Scroll tip geometries

\begin{tabular}{|c|c|}
\hline Scroll tip shape & Author \\
\hline single arc tip & - Blunier et al. $(2006,2009)[65,66]$ \\
\hline dual arc tip & $\begin{array}{l}\text { - Hirano et al. }(1987)[150] \\
\text { - Tsuji et al. }(2010)[155] \\
\text { - Bell et al. }(2012)[156]\end{array}$ \\
\hline PMP & $\begin{array}{l}\text { - Hirano et al. }(1989,1990)[151,152] \\
\text { - Liu et al. }(1992,1994)[157,158] \\
\text { - Lee and Wu }(1993,1995)[159,160] \\
\text { - Lee }(1996)[161] \\
\text { - Bell et al. }(2008,2012)[67,68,162] \\
\text { - Hao et al. }(2010)[163] \\
\text { - Hirano et al. }(2011)[164] \\
\text { - Song et al. }(2015)[165] \\
\text { - Wei et al. }(2015)[34]\end{array}$ \\
\hline dual arc tip and PMP & $\begin{array}{l}\text { - Liu et al. }(2004)[166] \\
\text { - Liu et al. }(2010)[118] \\
\text { - Bell et al. }(2011)[51]\end{array}$ \\
\hline $\begin{array}{l}\text { single arc tip, dual arc } \\
\text { tip and PMP }\end{array}$ & $\begin{array}{l}\text { - Terauchi }(1985)[167] \\
\text { - Bell et al. }(2010)[153] \\
\text { - Shaffer and Groll }(2012,2013) \\
\quad[122,123,168] \\
\text { - Guo }(2016)[75]\end{array}$ \\
\hline
\end{tabular}

Effects of scroll tip shape variations on the performance

Bell (2011) [51] used dual arc tip and PMP scroll tip design to treat the scroll compressor discharge region analytically. The PMP can be achieved in both cases which resulted in a larger built-in volume ratio. Shaffer and Groll $(2012,2013)[122,123,168]$ extended Gravesen's method to the tip region in their work to generate and compare the single arc, dual arc and perfect meshing profile configuration. The latter resulted in a higher built-in volume ratio and an extended and improved compression process. Bell et al. (2010) [153] also compared the single arc, the dual arc and the perfect meshing profile consisting of two arcs and a single line to create a discharge geometry which is manufacturable and has a sufficient mechanical strength. The latter was chosen due to the lack of robustness of the single arc scroll tip and the uncommon dual arc scroll tip solution. Guo (2016) [75] studied the scroll expander tip design with a geometrical model. It can be noted that the built-in volume ratio in a scroll expander consisting of a dual arc tip with PMP was higher compared to the single arc tip or the dual arc tip without a PMP configuration.

In summary of this section it can be said that the scroll tip geometry characterised by two arcs and a single line to reach the PMP at the central portion of the scrolls is the most common and promising solution. 


\section{Conclusions}

This paper provides a comprehensive review of the literature research for scroll expanders from the geometry point of view. In particular, the flow and heat transfer fields are determined by the scroll geometry and vice versa. Furthermore, the shape of the scroll profiles to form the working chambers including highly efficient surfaces are of essential significance in a scroll geometry in order to reach the optimum performance in ORC systems.

Geometrical approaches used for compressor models have been successfully integrated in scroll expander models. Thermodynamic modelling of the expander working process show a good agreement with experimental data. The survey has also revealed the need for high built-in volume ratios for expander applications in small ORC systems.

The review confirms that a bigger built-in volume ratio leads to the ability to perform at higher pressure ratio which in turn produces increased shaft power. However, the increase of the built-in volume ratio is associated with a large increase of the scroll profile length in a scroll expander. With a constant wall thickness, this increase is limited, because it raises sealing and lubrication problems and the efficiency decreases as a result of increasing internal leakages, heat transfer and friction losses.

It is possible to increase the built-in volume ratio without increasing the length of the scroll profiles by using scroll geometries with a variable wall thickness. Further evaluation with CFD simulations and experiments should be carried out since this is not only a promising candidate to improve the performance of ORC systems but may also open a broad new field of applications when a high pressure ratio is preferred.

Scroll profiles can be formed with a variety of other geometrical curves, such as spirals of Archimedes and twin spirals. Although the studies made of the twin-spiral geometry are limited, it may have the potential to overcome the geometric constraints of a scroll expander generated by an involute of a circle with a constant wall-thickness and to further improve the efficiency and the power output to make it suitable for particular applications.

From a survey of tip shape studies, the scroll tip shape characterised by two arc curves and a single line to reach the PMP at the central portion of the scroll suction area appears to be the most promising solution.

\section{Nomenclature}

$\begin{array}{ll}\text { a } & \text { base circle radius (mm) } \\ \text { A/C } & \text { Air Conditioning } \\ \text { CAE } & \text { Computer-Aided Engineering } \\ \text { CFD } & \text { Computational Fluid Dynamics } \\ \text { CO2 } & \text { Carbon Dioxide } \\ \text { COP } & \text { Coefficient of Performance } \\ \text { FEM } & \text { Finite element method } \\ \text { h } & \text { Scroll height (mm) } \\ \text { L } & \text { Tangential distance between inner and outer involute } \\ \text { LFEC } & \text { Liquid Flooded Ericsson Cycle } \\ \text { NH } & \text { Ammonia } \\ \text { ORC } & \text { Organic Rankine cycle } \\ \text { P } & \text { Power output (W) } \\ \text { PMP } & \text { Perfect Meshing Profile } \\ \text { PR } & \text { Pressure ratio (-) } \\ \text { p-V } & \text { Pressure-Volume } \\ \dot{Q} & \text { Heat transfer rate (W) } \\ \text { R22 } & \text { Chlorodifluoromethane } \\ \text { R123 } & 2,2 \text {-Dichloro-1,1,1-trifluoroethane } \\ \text { R134a } & 1,1,1,2-\text { Tetrafluoroethane } \\ \text { R245fa } & 1,1,1,3,3-\text { Pentafluoropropane } \\ \text { RE } & \text { Reverse Engineering } \\ \mathrm{r}_{o} & \text { orbiting radius of the moving scroll (mm) } \\ \mathrm{r}_{v} & \text { built-in volume ratio } \\ \mathrm{rpm} & \text { revolutions per minute (rad/s) } \\ \mathrm{t} & \text { scroll wall thickness (mm) } \\ \dot{W} & \text { Power (W) } \\ \mathrm{x} & \text { x-coordinate } \\ \text { y } & \text { y-coordinate } \\ & \end{array}$


$\alpha_{i} \quad$ initial angle of the inner involute (rad)

$\alpha_{o} \quad$ initial angle of the outer involute (rad)

$\Theta \quad$ Orbiting angle

$\varphi_{e} \quad$ involute ending angle (rad)

$\varphi_{i} \quad$ inner involute angle (rad)

$\varphi_{o} \quad$ outer involute angle (rad)

$\eta_{\text {cycle }} \quad$ cycle efficiency (\%)

$\eta_{\text {mech }}$ mechanical efficiency (\%)

$\eta_{s} \quad$ isentropic efficiency $(\%)$

$\eta_{\text {vol }} \quad$ volumetric efficiency $(\%)$

\section{Subscripts}

i inner involute

o outer involute

$\mathrm{s}$ isentropic

mech mechanical

vol volumetric

\section{References}

[1] H. Oomori and S. Ogino. Waste heat recovery of passenger car using a combination of rankine bottoming cycle and evaporative engine cooling system. Technical Report, SAE Technical Paper, 1993.

[2] T. Endo, S. Kawajiri, Y. Kojima, K. Takahashi, T. Baba, S. Ibaraki, T. Takahashi, and M. Shinohara. Study on maximizing exergy in automotive engines. Technical Report, SAE Technical Paper, 2007.

[3] R. Moro, P. Pinamonti, and M. Reini. Orc technology fosystems-wood to energy conversion in the furniture manufacturing industry. Thermal Science, 12(4):61-73, 2008.

[4] A. Rentizelas, S. Karellas, E. Kakaras, and I. Tatsiopoulos. Comparative techno-economic analysis of orc and gasification for bioenergy applications. Energy Conversion and Management, 50(3):674-681, 2009.

[5] T. Engin and V. Ari. Energy auditing and recovery for dry type cement rotary kiln systems - a case study. Energy Conversion and Management, 46(4):551-562, 2005.

[6] P.S. Bundela and V. Chawla. Sustainable development through waste heat recovery. American Journal of Environmental Sciences, 6(1):83$89,2010$.

[7] H. Müller-Steinhagen and F. Trieb. Concentrating solar power. A review of technology. Ingenia Inform QR Acad Eng., 18:43-50, 2004.

[8] S. Quoilin, M. Orosz, H. Hemond, and V. Lemort. Performance and design optimization of a low-cost solar organic rankine cycle for remote power generation. Solar Energy, 85(5):955-966, 2011.

[9] A. Lazzaretto, A. Toffolo, G. Manente, N. Rossi, and M. Paci. Cost evaluation of organic rankine cycles for low temperature geothermal sources. Proceedings of ECOS, pages 4-7, 2011.

[10] S. Quolilin, M. VanDenBroek, S. Declaye, P. Dewallef, and V. Lemort. Techno-economic survey of organic rankine cycle (orc) systems. Renewable and Sustainable Energy Reviews 22, pages 168-186, 2013.

[11] G. Qiu, H. Liu, and S. Riffat. Expanders for micro-chp systems with organic rankine cycle. Applied Thermal Engineering 31, pages $3301-3307,2011$.

[12] R. Zanelli and D. Favrat. Experimental investigation of a hermetic scroll expander-generator. in: Proc. Int. Compress. Eng. Conf., Purdue, Paper 1021, 1994

[13] V. Lemort, S. Quoilin, C. Cuevas, and J. Lebrun. Testing and modeling a scroll expander integrated into an organic rankine cycle. Applied Thermal Engineering 29, pages 3094-3102, 2009.

[14] J. Bao and L. Zhao. A review of working fluid and expander selections for organic rankine cycle. Renewable and Sustainable Energy Reviews 24 , pages $325-342,2013$.

[15] S. Quoilin. Sustainable energy conversion through the use of organic rankine cycles for waste heat recovery and solar applicaitons. PhD Thesis, University of Liège - Aerospace and Mechanical Engineering Department, 2011.

[16] T. Saitoh, N. Yamada, and S.-I. Wakashima. Solar rankine cycle system using scroll expander. J. Environ. Eng. 2, pages 708-719, 2007.

[17] D. Manolakos, G. Papadakis, S. Kyritsis, and K. Bouzianas. Experimental evaluation of an autonomous low-temperature solar rankine cycle system for reverse osmosis desalination. Desalination 203, pages 366-374, 2007.

[18] J.A. Mathias, J.J.R. Johnston, J. Cao, D.K. Priedeman, and R.N. Christensen. Experimental testing of gerotor and scroll expanders used in, and energetic and exergetic modeling of, an organic rankine cycle. J. Energy Resour. Tech. 131, pages 1-9, 2009.

[19] S.M.E. Hoque. Experimental investigation of an r134a based organic rankine cycle, master dissertation, university of ontario institute of technology, 2011.

[20] W. Gu, S. Sun, Y. Weng, and Y. Wang. Experimental study on low grade heat driven organic rankine cycle by scroll expander. Zhongguo Dianji Gongcheng Xuebao Proc Chin Soc Electr Eng, Vol.31, pages 20-25, 2011.

[21] B. Twomey. Experimental test results from qgece laboratory small-scale organic rankine cycle using a scroll expander. Queensland Geothermal Energy Centre of Excellence, http://espace.library.uq.edu.au, 2012.

[22] N. Zhou, X. Wang, Z. Chen, and Z. Wang . Experimental study on organic rankine cycle for waste heat recovery from low-temperature flue gas. Energy 55, pages 216-225, 2013.

[23] R. Bracco, S. Clemente, D. Micheli, and M. Reini. Experimental tests and modelization of a domestic-scale orc (organic rankine cycle). Energy, 58:107 - 116, 2013.

[24] L. Guangbin, Z. Yuanyang, Y. Qichao, W. Le, T. Bin, and L. Liansheng. Theoretical and experimental research on scroll expander used in small-scale organic rankine cycle system. Proc IMechE Part E: J Process Mechanical Engineering, Vol. 229(1):25-35, 2013.

[25] M. Jradi, J. Li, H. Liu, and S. Riffat. Micro-scale orc-based combined heat and power system using a novel scroll expander. Int. J. Low-Carbon Tech. 9, pages 91-99, 2014.

[26] P. Song, M. Wei, L. Shi, S. N. Danish, and C. Ma. A review of scroll expanders for organic rankine cycle systems. Applied Thermal Engineering 75, pages 54-64, 2015.

[27] H. Wang, R.B. Peterson, and T. Herron. Experimental performance of a compliant scroll expander for an organic rankine cycle. Proc. IMechE Vol. 223 Part A: J. Power and Energy, pages 863-872, 2009.

[28] OBRISTEngineering. https://www.obrist.at/compressor-expander-technology/scroll/ (accessed 11.01.2018).

[29] EXOES. exoes.com/en/waste-heat-recovery/products (accessed 11.01.2018).

[30] AirSquaredInc. https://airsquared.com/products/scroll-expanders/ (accessed 11.01.2018).

[31] EneftechInnovation and M. Kane. Research, development \& commercialization of orc modules in swithzerland. Schweizer ORC Symposium, 2014 .

[32] ECRInternational. Research, development and demonstration of micro-chp system for residential applications. 2010.

[33] H. Gao and Y. Jiang. Numerical simulation of unsteady flow in a scroll compressor. in: Proc. Int. Compress. Eng. Conf., Purdue, Paper $2337,2014$.

[34] M. Wei, P. Song, B. Zhao, L. Shi, Z. Wang, and C. Ma. Unsteady flow in the suction process of a scroll expander for an orc waste heat recovery system. Applied Thermal Engineering 78, 2015.

[35] P. Song, M. Wei, Z. Liu, and B. Zhao. Effects of suction port arrangements on a scroll expander for a small scale orc system based on cfd approach. Applied Energy 150, 2015. 
[36] H. Gao, H. Ding, and Y. Jiang. 3d transient cfd simulation of scroll compressors with the tip seal. IOP Conf. Series: Materials Science and Engineering 90, 2015.

[37] A. Suman, C. Buratto, N. Aldi, M. Pinelli, P. R. Spina, and M. Morini. A comparison between two different cfd approaches of a real scroll expander for micro-orc applications. 3rd International Seminar on ORC Power Systems, 2015.

[38] M. Morini, C. Pavan, M. Pinelli, E. Romito, and A. Suman. Analysis of a scroll machine for micro orc applications by means of a re/cfd methodology. Applied Thermal Engineering 80, pages 132-140, 2015.

[39] J. Wang, Y. Song, Q. Li, and D. Zhang. Novel structured dynamic mesh generation for cfd analysis of scroll compressors. Proc IMechE Part A: J Power and Energy, Vol. 229, 2015.

[40] A. Suman, S. Randi, N. Casari, M. Pinelli, and L. Nespoli. Experimental and numerical characterization of an oil-free scroll expander. Energy Procedia Volume 129, pages 403-410, 2017.

[41] P. Song, W. Zhuge, Y. Zhang, L. Zhang, and H. Duan. Unsteady leakage flow through axial clearance of an orc scroll expander. Energy Procedia Volume 129, pages 355-362, 2017.

[42] S. Sun, K. Wu, P. Guo, and J. Yan. Analysis of the three-dimensional transient flow in a scroll refrigeration compressor. Applied Thermal Engineering Volume 127, pages 1086-1094, 2017.

[43] L. Creux. Rotary engine, u.s. patent no. 801,182, october 3, 1905.

[44] H. Güttinger. Displacement machine for compressible media, u.s. patent 3,989,422, november $2,1976$.

[45] N.O. Young and J.E. McCullough. Scroll type positive fluid displacement apparatus, u.s. patent 3,884,599, may 20, 1975

[46] C.O.J. Montelius. Rotary compressor or motor, u.s. patent no. 2,324,168, july 13, 1943.

[47] G. Xiaojun, L. Liansheng, Z. Yuanyang, and S. Pengcheng. Research on a scroll expander used for recovering work in a fuel cell. Int. Journal of Thermodynamics, Vol.7, (No.1), pp.1-8, 2004.

[48] M. Hayano, S. Nagatomo, H. Sakata, and M. Hatori. Performance analysis of scroll compressor for air conditioners. in: Proc. Int. Compress. Eng. Conf., Purdue, Paper 575, 1986.

[49] E. Morishita, M. Sugihara, T. Inaba, and T. Nakamura. Scroll compressor analytical model. in: Proc. Int. Compress. Eng. Conf. Purdue, Paper 495, 1984.

[50] E. Morishita, M. Sugihara, and T. Nakamura. Scroll compressor dynamics (1st report, the model for the fixed radius crank). Bulletin of JSME Vol. 29, No. 248, 1986.

[51] I. H. Bell. Theoretical and Experimental Analysis of Liquid Flooded Compression in Scroll Compressors. PhD thesis, Purdue University, West Lafayette, Indiana, 2011.

[52] K. Tojo, M. Ikegawa, N. Maeda, S. Machida, and M. Shilbayashi. Computer modeling of scroll compressor with self adjusting back-pressure mechanism. in: Proc. Int. Compress. Eng. Conf., Paper 576, Purdue, 1986.

[53] S. Etemad and J. Nieter. Computational parametric study of scroll compressor efficiency, design, and manufacturing issues. in: Proc. Int. Compress. Eng. Conf., Purdue, Paper 602, 1988

[54] J.J. Nieter. Dynamics of scroll suction process. in: Proc. Int. Compress. Eng. Conf., Purdue, Paper 617, 1988.

[55] J.J. Nieter and D.P. Gagne. Analytical modeling of discharge flow dynamics in scroll compressors. in: Proc. Int. Compress. Eng. Conf. Purdue, Paper 795, 1992.

[56] T. Hirano, N. Matsumura, and K. Takeda. Development of high efficiency scroll compressors for air conditioners. in: Proc. Int. Compress. Eng. Conf. Purdue, Paper 603, 1988.

[57] T. Yanagisawa, M. D. Cheng, M. Fukuta, and T. Shimizu. Optimum operating pressure ratio for scroll compressor. in: Proc. Int. Compress. Eng. Conf., Purdue, Paper 732, 1990.

[58] J. Zhu, D. Wang, and Y. Li. Geometrical analysis of scroll compressor for high pressure ratio. in: Proc. Int. Compress. Eng. Conf., Purdue, Paper 1023, 1994.

[59] Z. Liu, G. Du, J. Gu, and X. Cao. Optimization of dimensional parameters of scroll compressor geometric model with arbitrary real number of turns. in: Proc. Int. Compress. Eng. Conf., Purdue, Paper $1178,1996$.

[60] N.P. Halm. Mathematical modeling of scroll compressor. Master's thesis, Master's thesis, Herrick kab., School of Mechanical Engineering, Purdue University, 1997.

[61] Y. Chen, N. P. Halm, E. A. Groll, and J. E. Braun. Mathematical modeling of scroll compressors - part i: compression process modeling. International Journal of Refrigeration 25, pages 731-750, 2002.

[62] Y. Chen, N. P. Halm, J. E. Braun, and E. A. Groll. Mathematical modeling of scroll compressors - part ii: overall scroll compressor modeling. International Journal of Refrigeration 25, pages 751-764, 2002.

[63] B. Wang, X. Li, and W. Shi. A general geometrical model of scroll compressors based on discretional initial angles of involute. International Journal of Refrigeration 28, pages 958-966, 2005.

[64] J. Gravesen and C. Henriksen. The geometry of the scroll compressor. Siam Review Vol. 43, No. 1, pages 113-126, 2001.

[65] B. Blunier, G. Cirrincione, and A. Miraoui. Novel geometric model of scroll compressors for the analytical description of the chamber volume. in: Proc. Int. Compress. Eng. Conf. Purdue, Paper 1745, 2006.

[66] B. Blunier, G. Cirrincione, Y. Herve, and A. Miraoui. A new analytical and dynamical model of a scroll compressor with experimental validation. International Journal of Refrigeration 32, pages 874-891, 2009.

[67] I. Bell, V. Lemort, J. Braun, and E. Groll. Development of liquid-flooded scroll compressor and expander models. in: Proc. Int. Compress. Eng. Conf. Purdue, Paper 1872, 2008.

[68] I. H. Bell, V. Lemort, E. A. Groll, J. E. Braun, G. B. King, and W. T. Horton. Liquid-flooded compression and expansion in scroll machines - part i: Model development. International Journal of Refrigeration 35, pages 1878-1889, 2012.

[69] V. Lemort, S. Quoilin, and J. Lebrun. Numerical simulation of a scroll expander for use in a rankine cycle. in: Proc. Int. Compress. Eng. Conf. Purdue, Paper 1324, 2008.

[70] V. Lemort and S. Quoilin. Designing scroll expanders for use in heat recovery rankine cycles. Technical report, Thermodynamics Laboratory, University of Liège, Belgium, 2009.

[71] J. Wang, L. Yang, X. Luo, S. Mangan, and J. W. Derby. Mathematical modeling study of scroll air motors and energy efficiency analysis part 1. IEEE/ASME Transactions on Mechatronics, VOL. 16, NO. 1, 2011.

[72] J. Wang, X. Luo, L. Yang, L. M. Shpanin, N. Jia, S. Mangan, and J. W. Derby. Mathematical modeling study of scroll air motors and energy efficiency analysis - part 2. IEEE/ASME Transactions on Mechatronics, VOL. 16, NO. 1, 2011.

[73] A. Legros, L. Guillaume, V. Lemort, M. Diny, I. Bell, and S. Quoilin. Investigation on a scroll expander for waste heat recovery on internal combustion engines. International conference on compressors and their systems, 2013.

[74] Z. Liu, G. Tian, M. Wei, P. Song, Y. Lu, G. Ashby, and A. P. Roskilly. Modelling and optimisation on scroll expander for waste heat recovery organic rankine cycle. Energy Procedia 75, pages 1603-1608, 2015.

[75] H. Guo. Design and manufacture of a scroll expander. Project report, Department of Mechanical Engineering Science, University of Surrey, 2016 .

[76] X. Zhang, Y. Xu, J. Xu, Y. Sheng, Z. Zuo, J. Liu, H. Chen, Y. Wang, and Y. Huang. Study on the performance and optimization of a scroll expander driven by compressed air. Applied Energy Vol.186, Part 3, pages 347-358, 2017.

[77] N. Ishii, S. Yamamoto, S. Muramatsu, M. Yamamura, and M. Takahashi. Optimum combination of parameters for high mechanical efficiency of a scroll compressor. in: Proc. Int. Compress. Eng. Conf., Purdue, Paper 798, 1992.

[78] N. Ishii, M. Yamarnura, S. Muramatsu, S. Yamada, and M. Takahashi. A study on high mechanical efficiency of a scroll compressor with fixed cylinder diameter. in: Proc. Int. Compress. Eng. Conf., Purdue, Paper 1055, 1994.

[79] N. Ishii, M. Sakai, K. Sano, S. Yamamoto, and T. Otokura. A fundamental optimum design for high mechanical and volumetric efficiency of compact scroll compressors. in: Proc. Int. Compress. Eng. Conf., Purdue, Paper 1176, 1996.

[80] R. Puff and M. Krueger. Influence of the main constructive parameters of a scroll compressor on its efficiency. in: Proc. Int. Compress. Eng. Conf., Purdue, Paper 797, 1992.

[81] S. Etemad and J. Nieter. Design optimization of the scroll compressor. Int J. Refrig. Vol. 12, 1989.

[82] E. Morishita and M. Sugihara. Some design problems of scroll compressor. Bulletin of JSME Vol. 29, No. 258, 1986.

[83] B. VanderKooy. Optimization of scroll compressor involute height with machining considerations. International Compressor Engineering Conference, 2004

[84] K. Terauchi. Scroll type compressor with wrap portions of different axial heights. U.S. Patent 4,477,238, 1984.

[85] A. Kawano and K. Terauchi. High efficiency scroll type compressor with wrap portions having different axial heights. U.S. Patent, 1984.

[86] T. Tateishi, H. Sato, H. Kobayashi, and H. Mizuno. Development of high performance 3d scroll compressor. International Compressor Engineering Conference, Paper $1744,2006$.

[87] T. Kuwahara, K. Watanabe, M. Takeuchi, H. Yamazaki, G. Yoshikawa, and K. Kitaguchi. Development of high-efficiency scroll compressor for automotive air conditioners. Mitsubishi Heavy Industries Technical Review Vol. 54 No.2, 2017.

[88] S. Clemente, D. Micheli, M. Reini, and R. Taccani. Energy efficiency analysis of organic rankine cycles with scroll expanders for cogenerative applications. Applied Energy 97, 2012

[89] M. Kane, D. Favrat, B. Gay, and O. Andres. Scroll expander organic rankine cycle (orc) efficiency boost of biogas engines. in: Proc. ECOS2007 Vol.2 Padova, pages 1017-1024, 2007.

[90] J. Manzagol, P. d'Harboullé, G. Claudet, and G. G. Baguer. Cryogenic scroll expander for claude cycle with cooling power of 10 to 100 watts 
at 4.2k. AIP Conference Proceedings 613, Vol. 47, 2002

[91] J.-C. Chang, C.-W. Chang, T.-C. Hung, J.-R. Lin, and K.-C. Huang. Experimental study and cfd approach for scroll type expander used in low-temperature organic rankine cycle. Applied Thermal Engineering 73, pages 1444-1452, 2014.

[92] J.-C. Chang, T.-C. Hung, Y.-L. He, and W. Zhang. Experimental study on low-temperature organic rankine cycle utilizing scroll type expander. Applied Energy 155, pages 150-159, 2015.

[93] J. Hugenroth, J. Braun, E. Groll, and G. King. Liquid-flooded ericsson cycle cooler part 2 - experimental results. in: Proc. Int. Refrig. Air Cond. Conf. Purdue Paper 824, 2006.

[94] B.J. Woodland, J.E. Braun, E.A. Groll, and W.T. Horton. Experimental testing of an organic rankine cycle with scroll-type expander. Publications of the Ray W. Herrick Laboratories, Paper 52, 2012.

[95] L. C. Mendoza, J. Navarro-Esbrí, J. C. Bruno, V. Lemort, and A. Coronas. Characterization and modeling of a scroll expander with air and ammonia as working fluid. Applied Thermal Engineering, 70:630-640, 2014.

[96] L. C. Mendoza, D. S. Ayou, J. Navarro-Esbrí, J. C. Bruno, and A. Coronas. Small capacity absorption systems for cooling and power with a scroll expander and ammonia based working fluids. Applied Thermal Engineering, 72:258-265, 2014.

[97] Z. Miao, J. Xu, and K. Zhang. Experimental and modeling investigation of an organic rankine cycle system based on the scroll expander. Energy, 134:35-49, 2017.

[98] M. Kane, D. Larrain, D. Favrat, and Y. Allani. Small hybrid solar power system. Energy 28, pages 1427-1443, 2003.

[99] V. Lemort, S. Declaye, and S. Quoilin. Experimental characterization of a hermetic scroll expander for use in a micro-scale rankine cycle Proceedings of the Institution of Mechanical Engineers Part A Journal of Power and Energy Vol. 226, 2012.

[100] X. Yang, J. Xu, Z. Miao, J. Zhou, and C. Yu. Operation of an organic rankine cycle dependent on pumping flow rates and expander torques. Energy, 90:864-878, 2015.

[101] X. Yang, J. Xu, Z. Miao, J. Zou, and F. Qi. The definition of non-dimensional integration temperature difference and its effect on organic rankine cycle. Applied Energy, 167:17-33, 2016.

[102] Y.-Q. Feng, T.-C. Hung, S.-L. Wu, C.-H. Lin, B.-X. Li, K.-C. Huang, and J. Qin. Operation characteristic of a r123-based organic rankine cycle depending on working fluid mass flow rates and heat source temperatures. Energy Conversion and Management, $131: 55-68,2017$.

[103] T. Yanagisawa, M. Fukuta, Y. Ogi, and T. Hikichi. Performance of an oil-free scroll-type air expander. in: Proceedings of the IMechE Conference on Compressors and their Systems, 2001.

[104] L. Guangbin, Z. Yuanyang, L. Liansheng, and S. Pengcheng. Simulation and experiment research on wide ranging working process of scroll expander driven by compressed air. Applied Thermal Engineering, 30:2073-2079, 2010.

[105] S.-C. Yang, T.-C. Hung, Y.-Q. Feng, C.-J. Wu, K.-W. Wong, and K.-C. Huang. Experimental investigation on a $3 \mathrm{kw}$ organic rankine cycle for low-grade waste heat under different operation parameters. Applied Thermal Engineering, 113:756 - 764, 2017.

[106] P. Gao, L. Jiang, L.W. Wang, R.Z. Wang, and F.P. Song. Simulation and experiments on an orc system with different scroll expanders based on energy and exergy analysis. Applied Thermal Engineering 75, pages 880-888, 2015.

[107] K. Qiu, M. Thomas, and M. Douglas. Investigation of a scroll expander driven by compressed air and its potential applications to orc. Applied Thermal Engineering, 135:109-115, 2018.

[108] S. Declaye, S. Quoilin, L. Guillaume, and V. Lemort. Experimental study on an open-drive scroll expander integrated into an orc (organic rankine cycle) system with r245fa as working fluid. Energy 55, pages 173-183, 2013.

[109] R. Peterson, H. Wang, and T. Herron. Performance of a small-scale regenerative rankine power cycle employing a scroll expander. P. $I$. Mech. Eng. A-J. Pow., Vol.222, pages 271-282, 2008.

[110] G. Demirkaya, R. Vasquez Padilla, D.Y. Goswami, E. Stefanakos, and M.M. Rahman. Analysis of a combined power and cooling cycle for low-grade heat sources. Int. J. Energy Res. 35 (13), pages 1145-1157, 2011.

[111] H.A. Ingley, R. Reed, and D.Y. Goswami. Optimization of a scroll expander applied to an ammonia/water combined cycle system for hydrogen production. Proceedings of the Solar World Congress 2005: Bringing Water to the World, Including Proceedings of 34 th ASES Annual Conference and Proceedings of 30th National Passive Solar Conference, pages 2089-2100, 2005.

[112] J. W. Bush and W. P. Beagle. Derivation of a general relation governing the conjugacy of scroll profiles. in: Proc. Int. Compress. Eng. Conf., Purdue, Paper 902, 1992

[113] J. W. Bush, W. P. Beagle, and M. E. Housman. Maximizing scroll compressor displacement using generalized wrap geometry. in: Proc. Int. Compress. Eng. Conf., Purdue, Paper 981, 1994.

[114] D. P. Gagne and J. J. Nieter. Simulating scroll compressors using a generalized conjugate surface approach. in: Proc. Int. Compress. Eng. Conf., Purdue, Paper 1163, 1996.

[115] D. Lindsay and R. Radermacher. Theory and application of alternative scroll geometries. in: Proc. Int. Compress. Eng. Conf., Purdue, Paper 1453,2000

[116] J. Rak, S. Pietrowicz, and Z. Gnutek. The scroll compressor with internal cooling system in cryogenics applications. in: Proc. Int. Compress. Eng. Conf., Purdue, Paper 2365, 2014.

[117] J. Rak, S. Pietrowicz, and Z. Gnutek. The scroll compressor with internal cooling system - conception and cfd analysis. in: Proc. Int. Compress. Eng. Conf., Purdue, Paper 2364, 2014.

[118] Y. Liu, C. Hung, and Y. Chang. Study on involute of circle with variable radii in a scroll compressor. Mechanism and Machine Theory 45, pages $1520-1536,2010$

[119] Y. Liu, Y. Tang, Y. Chang, and Y. Yang. Optimum design of scroll profiles created from involute of circle with variable radii by using finite element analysis. Mechanism and Machine Theory 55, pages 1-17, 2012.

[120] K. Tojo and H. Ueda. Scroll type fluid machine with an involute spiral based on a circle having a varying radius, u.s. patent no. 5,425,626, jun. 20,1995 .

[121] J. Gravesen, C. Henriksen, and P. Howell. Danfoss: Scroll optimization. Technical report, 1998.

[122] B. R. Shaffer and E. A. Groll. Parametric representation of scroll geometry with variable wall thickness. in: Proc. Int. Compress. Eng. Conf., Purdue, Paper 1268, 2012.

[123] B. R. Shaffer and E. A. Groll. Variable wall thickness scroll geometry modeling with use of a control volume approach. International Journal of Refrigeration 36, pages 1809-1820, 2013.

[124] R. Dickes. Design and fabrication of a variable wall thickness two-stage scroll expander to be integrated in a micro-solar power plant. Master's thesis, University of Liège, 2013.

[125] P. Bin, V. Lemort, A. Legros, Z. Hongsheng, and G. Haifeng. Variable thickness scroll compressor performance analysis - part i: Geometric and thermodynamic modeling. Proc IMechE Part E: J Process Mechanical Engineering O (O) $18,2016$.

[126] P. Bin, V. Lemort, A. Legros, Z. Hongsheng, and G. Haifeng. Variable thickness scroll compressor performance analysis - part ii: Dynamic modeling and model validation. Proc IMechE Part E: J Process Mechanical Engineering O(0) 19, 2016.

[127] E.B. Muir, R.W. Griffith, and G.W. Lilienthal. Scroll-type machine with rotation controlling means and specific wrap shape, u.s. patent no. $4,609,334$, sep. 2., 1986 .

[128] L. Li, P. Shu, and Y. Yu. Effect of scroll wraps on performances of scroll compressor. in: Proc. Int. Compress. Eng. Conf., Purdue, Paper $1167,1996$.

[129] L.-S. Li, P.-C. Shu, and Y.-Z. Yu. The effect of scroll wraps on the performance of scroll compressors. Int J. Refrig. Vol. 20, pages 326-331, 1997 .

[130] L. Wang and J. Chen. Inherent engagement mechanism study of profile of scrolls. Proc. of SPIE Vol. 6040, 2005.

[131] L. Wang, J. Chen, Y. Zhao, and S.H. Hussain. Research on the natural meshing mechanism and testing analysis of scroll profiles for refrigeration scroll compressor. Sci. China Tech. Sci. Vol.53 No.10, 2010.

[132] G. Wang. Theoretical and experimental research on the scroll compressor with arc-arc-line unit combined profile. Journal of Mechanical Engineering Vol. 46, No.10, 2010.

[133] G. Wang. Experimental research of the performance of a scroll compressor with unit combined profile for automobile at variable speed. School of Mechanical Engineering, University of Science and Technology Beijing, 2011.

[134] G. Wang. Theoretical research of gas forces on the scroll compressor with unit combined profile for automobile. School of Mechanical Engineering, University of Science and Technology Beijing, 2011.

[135] L. C. Mendoza, S. Lemofouet, and J. Schiffmann. Testing and modelling of a novel oil-free co-rotating scroll machine with water injection. Applied Energy 185, pages 201-213, 2017.

[136] R. E. Utter, C. M. Lin, and M. P. Mackefresh. Radial compliance mechanism for co-rotating scroll apparatus. U.S. Patent No. 5,713,731,

[137] L. M. Toledo, A. Iglesias, D. Favrat, and J. Schiffmann. Experimental investigation of water injection in an oil-free co-rotating scroll machinery for compressed air energy storage. International Compressor Engineering Conference, Paper 2324, 2014.

[138] A.Iglesias and D.Favrat. Innovative isothermal oil-free co-rotating scroll compressorexpander for energy storage with first expander tests. Energy Conversion and Management, Vol. 85, pages 565-572, 2014.

[139] L. C. Mendoza and J. A. Schiffmann. Co-rotating scroll machinery applied to vapor power and vapor compression cycles. 24 th IIR International Congress of Refrigeration (ICR2015), pages 16-22, 2015.

[140] R. W. Shaffer, B. R. Shaffer, and R. Vigil. Scroll type device incorporating spinning or co-rotating scrolls. Pub. No.: US2017/0051741 A1.

[141] P. McTaggart. Development of a hybrid compressor/expander module for automotive fuel cell applications. Final Technical Report for the 
U.S. Department of Energy, 2004

[142] B. Peng, H. Zhang, L. Zhang, and Z. Liu. Stress and deformation analyses of twin-spirals scroll plates based on cae. in: Proc. Int. Compress. Eng. Conf., Purdue, Paper 1924, 2008

[143] B. Peng, L. Zhang, R.-Z. Zhao, H.-S. Zhang, and Y.-Q. Zheng. Structure design of twin-spirals scroll compressor based on 3c. Journal of Software, Vol. 7, No. 9, 2012

[144] J. Qiang. General geometrical model of scroll compression chamber for scroll fluid machine. Journal of Fluids Engineering Vol. 132, 2010.

[145] J. Qiang. Study on basic parameters of scroll fluid machine based on general profile. Mechanism and Machine Theory 45, pages 212-223,

2010 .

[146] J. Qiang, B. Peng, and Z. Liu. Dynamic model for the orbiting scroll based on the pressure in scroll chambers - part 1: Analytical modeling. International Journal of Refrigeration 36, pages 1830-1849, 2013.

[147] Z.L. Gu, S.Y. Feng, and Y.Z. Yu. Study on the characteristics of scroll compressor with multiple spirals. in: Proceedings of the 1997's International Compressor Technique Conference Chengdu China, pages 205-208, 1997.

[148] Z.Q. Liu, J. Wang, and J.Q. Qiang. Scroll fluid machine and scroll compressor. China Machine Press, 2009.

[149] J. Qiang, B. Peng, and Z. Liu. Dynamic model for the orbiting scroll based on the pressures in scroll chambers - part 2: Iinvestigations on scroll compressors and model validation. International Journal of Refrigeration 36, pages 1850-1865, 2013.

[150] T. Hirano and K. Hagimoto. Rotary type fluid machine, u.s. patent no. 4,678,415, jul. 7, 1987.

[151] T. Hirano, K. Hagimoto, and K. Takeda. Scroll-type fluid machine with specific inner curve segments, u.s. patent no. $4,856,973$ aug. $15,1989$.

[152] T. Hirano, K. Hagimoto, and M. Maada. Scroll profiles for scroll fluid machines. MHI Tech Rev. 27 (1), pages 35-41, 1990.

[153] I.H. Bell, E.A. Groll, J.E. Braun, and G.B. King. Update on scroll compressor chamber geometry. in: Proc. Int. Compress. Eng. Conf. Purdue, Paper 2033, 2010.

[154] T. Liu and B. Peng. Geometry models of embedded-type-shaft scroll and their influence on dynamic property of scroll machine. in: Proc. Int. Compress. Eng. Conf. Purdue, Paper 1928, 2008.

[155] T. Tsuji, N. Ishii, S. Kiyoshi, K. Anami, and A. Hiwata. On the development of optimally efficient compact scroll compressors for refrigerators. in: Proc. Int. Compress. Eng. Conf., Purdue, Paper 2008, 2010.

[156] I.H. Bell, E.A. Groll, J.E. Braun, G.B. King, and W.T. Horton. Optimization of a scroll compressor for liquid flooding. International Journal of Refrigeration 35, pages 1901-1913, 2012.

[157] Z. Liu, G. Du, S. Yu, and M. Wang. The graphic method of modified wrap scroll compressor. in: Proc. Int. Compress. Eng. Conf., Purdue, Paper 904,1992 .

[158] Z. Liu, G. Du, Z. Qi, and J. Gu. The conjugacy analysis of modified part of scroll profiles. in: Proc. Int. Compress. Eng. Conf., Purdue, Paper 1024, 1994.

[159] Y.R. Lee and W.F. Wu. Proc. of the Tenth National Conf. on Mechanical Engineering Mechanical Design Hsinchu Taiwan, page 199,

[160] Y.-R. Lee and W.-F. Wu. On the profile design of a scroll compressor. International Journal of Refrigeration, Vol. 18, No. 5, pages 308-317,

[161] Y.-R. Lee and W.-F. Wu. A study of planar orbiting mechanism and its applications to scroll fluid machinery. Mech. Math. Theory Vol. 31 , No. 5, pages $705-716,1996$.

[162] I.H. Bell, V. Lemort, E.A. Groll, J.E. Braun, G.B. King, and W.T. Horton. Liquid flooded compression and expansion in scroll machines part 2: Experimental testing and model validation. International Journal of Refrigeration 35, pages 1890-1900, 2012.

[163] J.Y. Hao, Y.Y. Zhao, L.S. Li, Z.Z. Wang, and P.C. Shu. Theoretical and experimental study on the performance of co2 hermetic scroll compressor. Proc. IMechE Vol. 224 Part A: J. Power and Energy, 2010.

[164] T. Hirano, K. Hagimoto, and M. Maada. Study on scroll profiles for scroll fluid machines. Trans. Jpn. Soc. Refrig. Air. Cond. 8, pages $53-64,2011$

[165] P. Song, M. Wei, Z. Liu, and B. Zhao. Effects of suction port arrangements on a scroll expander for a small scale orc system based on cfd approach. Applied Energy 150, pages 274-285, 2015.

[166] T. Liu and Z.Q. Liu. Study on geometry theory of trigonometric-curve modification of scroll profile for scroll compressor. in: Proc. Int. Compress. Eng. Conf. Purdue, Paper 1659, 2004.

[167] K. Terauchi and M. Hiraga. Scroll type fluid compressor with thickened spiral elements, u.s. patent no. 4,547,137, oct. $15,1985$.

[168] B.R. Shaffer. Performance Analysis of Non-Metallic Dry Running Scroll Compressors. PhD thesis, Purdue University, 2012. 